TI 2012-078/3

Tinbergen Institute Discussion Paper
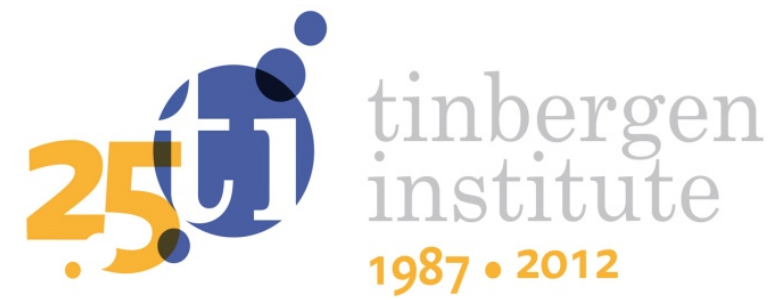

\title{
Catastrophic Medical Expenditure Risk
}

\author{
Gabriela Flores ${ }^{1}$ \\ Owen O'Donnel/2
}

1 Institute of Health Economics and Management, University of Lausanne, and Institute of Health Policy and Management, Erasmus University Rotterdam;

2 Erasmus School of Economics, Erasmus University Rotterdam, and University of Macedonia, Greece 
Tinbergen Institute is the graduate school and research institute in economics of Erasmus University Rotterdam, the University of Amsterdam and VU University Amsterdam.

More TI discussion papers can be downloaded at http://www.tinbergen.nl

Tinbergen Institute has two locations:

Tinbergen Institute Amsterdam

Gustav Mahlerplein 117

1082 MS Amsterdam

The Netherlands

Tel.: +31(0)205251600

Tinbergen Institute Rotterdam

Burg. Oudlaan 50

3062 PA Rotterdam

The Netherlands

Tel.: +31(0)10 4088900

Fax: $+31(0) 104089031$

Duisenberg school of finance is a collaboration of the Dutch financial sector and universities, with the ambition to support innovative research and offer top quality academic education in core areas of finance.

DSF research papers can be downloaded at: http://www.dsf.nl/

Duisenberg school of finance

Gustav Mahlerplein 117

1082 MS Amsterdam

The Netherlands

Tel.: +31(0)20 5258579 


\title{
CATASTROPHIC MEDICAL EXPENDITURE RISK
}

\author{
GABRIEla Flores ${ }^{\mathrm{A}, \mathrm{B}, \dagger}$, OWEN O’DONNELL ${ }^{\mathrm{C}, \mathrm{D}, \mathrm{E}, \ddagger}$ \\ ${ }^{A}$ Institute of Health Economics and Management, University of Lausanne, Switzerland \\ B Institute of Health Policy and Management, Erasmus University Rotterdam, the Netherlands \\ ${ }^{C}$ Erasmus School of Economics, Erasmus University Rotterdam, the Netherlands \\ D Timbergen Institute, the Netherlands \\ E University of Macedonia, Greece
}

July 23, 2012

\begin{abstract}
Medical expenditure risk can pose a major threat to living standards. We derive decomposable measures of catastrophic medical expenditure risk from reference-dependent utility with loss aversion. We propose a quantile regression based method of estimating risk exposure from cross-section data containing information on the means of financing health payments. We estimate medical expenditure risk in seven Asian countries and find it is highest in Laos and China, and is lowest in Malaysia. Exposure to risk is generally higher for households that have less recourse to self-insurance, lower incomes, wealth and education, and suffer from chronic illness.
\end{abstract}

JEL Classification: D12, D31, D80, I13, I15

Keywords: medical expenditures, catastrophic payments, downside risk, reference-dependent utility, Asia

Acknowledgements: This work was funded through EU-FP7 research grant HEALTH-F2-2009-223166HEFPA on "Health Equity and Financial Protection in Asia". Comments received on presentations made at CORE (Louvain-la-Neuve), iHEA (Toronto), SPPH+ (Grindelwald), $3^{\text {rd }}$ HEFPA wokshop (Hanoi) and Darmstadt are gratefully acknowledged.

†gabriela.flores@unil.ch

$\ddagger$ odonnell@ese.eur.nl 


\section{INTRODUCTION}

Uninsured medical expenditures can pose a major threat to living standards. This is particularly true in low and middle income countries with little formal health insurance coverage, but it can also be the case in high income countries, such as the US, in which out-of-pocket (OOP) payments finance a large proportion of spending on health care. Provision of financial protection against medical expenditure risks is widely regarded to be a central objective against which the performance of health systems should be assessed (World Health Organization 2000; World Health Organization 2010). One approach to measuring success in this respect defines OOP payments for health care as catastrophic if they exceed some proportion of income (Wagstaff and Van Doorslaer 2003), or capacity to pay (Xu, Evans et al. 2003). Households that spend more than a certain fraction of their budgets on health care are presumed to have experienced a catastrophic fall in living standards. Others that were exposed to risks without actually incurring medical expenditures, either because they were fortunate not to fall sick or because they could not afford treatment, are ignored. This is a major limitation. Identification of the welfare losses and behavioural consequences of exposure to risk necessarily requires adoption of an ex ante perspective.

The risk premium, a widely used measure of medical expenditure risk, weights prospects both above and below the expected value. More than half a century ago, Roy (1952) argued that this is inconsistent with common notions of risk, which, he suggested, view it as the danger of a bad outcome; something worse than expected, for example. A measure of catastrophic medical expenditure risk should focus on the prospect of contracting an illness that requires spending on health care to such a degree that the household's standard of living is substantially reduced, perhaps to subsistence levels. We derive such a measure from a model of reference-dependent utility (RDU) (Sugden 2003; Köszegi and Rabin 2006) with loss aversion (Kahneman and Tversky 1979). An advantage of this approach over previous measures of catastrophic health payments is that the threshold level of expenditure is not an ad hoc imposition of the analyst but is presumed to be integral to the preferences of the household. There is a feeling of loss when medical expenditure rises so high that some aspired level of consumption cannot be realised. Consistent with models of disappointment (Bell 1985; Loomes and Sugden 1986), we propose that the reference is defined in relation to expectations, although we recognise arguments for defining the threshold as a proportion of income.

We assume that utility is derived from non-medical consumption, which is threatened by medical expenditure needs. If insurance and credit options are constrained, as they typically are in the developing world, then medical needs can only be accommodated by cutting back on other consumption. Extremely large draws from the distribution of medical expenditure translate into extremely low draws from the distribution of non-medical consumption. We measure exposure to this downside risk. In focusing on the mass of the distribution beyond some threshold, the approach is consistent with the existing measure of catastrophic payments. A crucial difference is that the existing approach obtains an aggregate measure by summing across the distribution of medical expenditures actually incurred by households. Our measure is 
at the household level. We measure each household's exposure to catastrophic risks by summing over the ex ante distribution of medical expenses that it faces. This allows us to go beyond measurement of the average level of risk in a population to identification of the distribution of risk and its correlates, which is potentially useful in assessing the targeting of proposed extensions of health insurance. As far as we are aware, this is the first paper to measure downside consumption risk arising from medical expenses. The proposed measure can be decomposed into the probability that spending on health care pushes consumption below some reference point, the loss due to the predictably low level of consumption if it does fall below the threshold and the loss arising from the medical expenses induced variability of consumption below the threshold.

Feenberg and Skinner (1994) use longitudinal data to examine the time series properties of OOP payments for medical care incurred by the elderly in the US and estimate exposure to catastrophic payments (defined as exceeding one-fifth of income). They restrict attention to the probability of incurring such payments and do not seek to measure the utility loss from catastrophic medical expenditure risk. Our intention is to develop a measure for application primarily in low and middle income countries where health insurance cover is limited. Recognising the limited availability of long panels including data on OOP payments in developing countries, our goal is to make inferences about households' ex ante exposure to health expenditure risks within the constraints imposed by cross-section data. This inevitably involves strong assumptions. One must use the cross-sectional dispersion of expenditures across households with similar characteristics to approximate the longitudinal variability faced by any one of those households. We do this using quantile regressions that exploit information on the means of financing health payments to simulate the distribution of medical expenditures that are at the expense of non-medical consumption.

We illustrate the measure and method using comparable data from the World Health Surveys (World Health Organization 2011) for seven low and middle income Asian countries. Our downside risk measures are only weakly correlated with realised medical care budget shares and are not particularly strongly correlated with the risk premium, indicating that they provide additional information. Exposure to risk is generally higher for households that have less recourse to self and informal insurance through savings, borrowing, sale of assets, etc., and in the two countries for which suitable data are available (China and Malaysia), households with mandatory health insurance cover face less risk. Lower income, lower wealth, lower education and chronic illness are all associated with greater medical expenditure risk. Exposure to risk highest in Laos, one of the poorest countries examined where there is little formal health insurance and only meagre public health care provision. But it is next highest in China, which is not one of the poorest countries. Risk is lowest in Malaysia, the highest income country with a developed public health care system.

In the next section, we introduce measures of catastrophic medical expenditure risk derived from RDU. The third section presents the method of simulating the distributions of OOP payments and non-medical 
consumption faced by each household. In the fourth section, we describe the World Health Survey data and results from the empirical illustration are presented in the fifth section. The final section acknowledges limitations of the approach and points to directions for future research.

\section{REFERENCE-DEPENDENT RISK MEASURES}

Set up and assumptions

Each household faces a distribution of OOP health payments, a non-negative random variable $M_{i}$. It is able to finance $\theta_{i}\left(m_{i}\right) \in(0,1)$ of each realisation of OOP payments from saving, selling assets, borrowing or some other means of self or informal insurance that we will refer to as a 'coping strategy'. The remaining proportion must be paid for by sacrificing non-medical consumption. Note that the proportion that can be financed through coping strategies is allowed to depend on the level of expenditure. Savings, assets and access to credit are limited. It is assumed the household has knowledge

of its financing function, $\theta_{i}\left(m_{i}\right)$. It faces uncertainty over the level of OOP payments but not its ability to finance these. This assumption is necessary in order to translate uncertainty over the distribution of OOP payments into uncertainty over the distribution of non-medical consumption. It is plausible to assume that the household knows how much of any level of medical expenditures could be financed from its savings. The assumption is stronger with respect to access to credit and the prices at which assets could be sold.

Non-medical consumption, $C_{i}$, is a non-negative random variable, the realisation of which depends on the household's income, the realised level of OOP payments and the household's ability to finance this. It is assumed that household income is non-stochastic. This is a strong assumption, ruling out health shocks that simultaneously reduce earnings capacity and raise spending on health care. It is made because our objective is to focus exclusively on risk arising from medical expenditures. Under these assumptions, uncertainty over non-medical consumption arises only from uncertainty over health payments. Provided the household can finance some OOP payments from coping strategies, the variability in $C_{i}$ will be less than the variability in $M_{i}$.

We aim to capture the risk of a deficit in non-medical consumption below a reference level $\left(\xi_{i}\right)$ deriving from an excess of OOP payments not financed from coping strategies above a threshold. Let us represent OOP payments that are at the expense of non-medical consumption by $\tilde{M}_{i}=\left[1-\theta_{i}\left(M_{i}\right)\right] M_{i}$. This random variable is bounded from below by zero and above by the household's (assumed fixed) HaigSimons income, $\tilde{y}_{i}$. Actual medical expenditures can exceed income but this requires a reduction in net worth, the consequences of which are not captured by our approach. Under the additional assumptions 
that net worth is not used to finance non-medical consumption and there is no saving in the current period, $\tilde{y}_{i}=C_{i}+\tilde{M}_{i}$.

Specify reference-dependent utility (dropping the household indicator, $\imath$ ) as,

$$
U(c \mid \xi)= \begin{cases}u(c) & \text { if } c \geq \xi \\ u(c)+v(c \mid \xi) & \text { if } c<\xi\end{cases}
$$

where $u(c)$ is an increasing, concave function representing enjoyment of the amount of consumption and $v(c \mid \xi)$ represents the feeling of loss when consumption does not reach the reference level (Köszegi and Rabin, 2006). With $v(c \mid \xi)<0$ and $v^{\prime}(c \mid \xi)>0$ there is loss aversion (Kahneman and Tversky 1979). The failure to reach the reference consumption level causes disconcertion, with the result that utility falls by more than indicated by pure consumption utility $(u(c))$ as consumption falls below the threshold. ${ }^{1}$

Expected utility can be decomposed into three parts as follows (Jarrow and Zhao 2006),

$$
E[U(C \mid \xi)]=u(E[C])+\{E[u(C)]-u(E[C])\}+\int_{0}^{\xi} v(c \mid \xi) d F_{C}
$$

where $F_{C}$ is the cumulative distribution of $C$. The first term is pure consumption utility at the expected value of non-medical consumption and the second term is the welfare loss arising from diminishing marginal (pure consumption) utility and the variability of consumption over the full range of the distribution. This is what the risk premium would capture. The third term is the welfare loss due to the risk that consumption falls below the threshold, as well as its variability below the threshold, and the existence of loss aversion. This loss, which is the object of a downside risk measure (Jarrow and Zhao 2006), is what we wish to capture with measures of catastrophic health payments.

In the following sub-sections, we consider various specifications of the downside risk measure, $\operatorname{DRM}\left(F_{C} ; \xi\right)=-\int_{0}^{\xi} v(c \mid \xi) d F_{C}$.

\section{Lower partial moments}

Specifying the reference-dependent part of utility as a power function of the deficit in consumption from the reference level $\left(v(c \mid \xi)=-(\xi-c)^{\alpha}\right)$ leads to lower partial moment (LPM) measures of downside risk (Fishburn 1977),

\footnotetext{
${ }^{1}$ While the loss aversion of this specification is consistent with Prospect Theory (Kahneman and Tversky, 1979), we do not impose other components of this theory. Consistent with RDU models, such as Sugden (2003) and Kőszegi and Rabin, 2006), utility (value) is not solely determined by the gain/loss but also by the level of consumption. Further, as will be explained below, we do not impose convexity of utility below the threshold.
} 


$$
\operatorname{DRM}_{\alpha}^{L P M}\left(F_{C} ; \xi\right)=\int_{0}^{\xi}(\xi-c)^{\alpha} d F_{C}=L P M_{\alpha}\left(F_{C} ; \xi\right), \quad \alpha \geq 0
$$

These are expected deviations below the reference consumption level. Under the assumptions made above about the relationship between medical and non-medical expenditures, the lower partial moments of the distribution of non-medical consumption correspond to the upper partial moments (UPM) of the distribution of medical expenditures not financed from coping strategies, $F_{\tilde{M}}$.

$$
\begin{aligned}
U P M_{\alpha}\left(F_{\tilde{M}} ; \zeta\right) & =\int_{\zeta}^{\tilde{y}}(\tilde{m}-\zeta)^{\alpha} d F_{\tilde{M}}=\int_{\zeta}^{\tilde{y}}((\tilde{y}-\zeta)-(\tilde{y}-\tilde{m}))^{\alpha} d F_{\tilde{M}} \\
& =\int_{0}^{\xi}(\xi-c)^{\alpha} d F_{C}=L P M_{\alpha}\left(F_{C} ; \xi\right), \quad \alpha \geq 0
\end{aligned}
$$

where $\zeta$ is the threshold above which medical expenditures are considered catastrophic and $\xi=\tilde{y}-\zeta$.

$L P M_{0}$ is the probability that the household's non-medical consumption falls below the threshold. This is the relevant risk measure under Roy's (1952) Safety First Principle that priority is "to reduce as far as is possible the chance of a catastrophe occurring" (p.432). But with this parameterisation there is actually no loss aversion - the slope of the utility function is $u^{\prime}(c)$ on both sides of the threshold. With $0<\alpha<1$, the reference-dependent component of utility is convex. If the pure consumption component is not sufficiently concave, the convexity of $v(c \mid \xi)$ could dominate, implying risk loving behaviour below the reference point. Such preferences, which are an important component of prospect theory, are evident in experiments that find decreasing sensitivity to losses the larger are those losses (Kahneman and Tversky 1979; Fennema and Assen 1998; Abdellaoui 2000). However, this evidence comes from experiments based on low stakes lotteries conducted in high income countries. For catastrophic losses that could reduce consumption to subsistence levels, concavity below the threshold is arguably more plausible (Kale 2006). A recent experiment conducted among poor rural households in Benin finds greater risk aversion in the domain of losses than in gains (Gheyssens and Günther 2012).

$L P M_{1}$ is the household's expected shortfall from the threshold. This downside risk measure is insensitive to the distribution of non-medical consumption below the threshold, which reduces risk aversion over this range of the distribution. Absolute risk aversion below the reference point is less than it would be in the absence of reference-dependent utility and it is more likely to be increasing in consumption up to threshold. ${ }^{2}$ Setting $\alpha>1$ ensures that the lower partial moment is sensitive to the distribution below the

2 The Arrow-Pratt absolute risk aversion (ARA) index is $-u^{\prime \prime}(c) / u^{\prime}(c)$ in the absence of RDU and $-u^{\prime \prime}(c) /\left(u^{\prime}(c)+1\right)$ in its presence. So, at any level of consumption below the reference point, ARA is lower with RDU. Without RDU, $\partial A R A / \partial c=\left(-u^{\prime \prime \prime}(c) / u^{\prime}(c)\right)+A R A^{2}$. Assuming $u^{\prime \prime \prime}(c)>0$, non-increasing ARA requires that the magnitude of the first 
threshold but is not sufficient to obtain plausible higher order risk preferences. Downside risk aversion (Menezes, Geiss et al. 1980) (equivalently prudence (Kimball, 1990)) refers to the preference for risk to be located at higher, rather than lower, levels of wealth and, under expected utility, corresponds to a positive third derivative of the utility function. With $1<\alpha<2$, the third derivative of $v(c \mid \xi)=-(\xi-c)^{\alpha}$ is negative and so any downside risk aversion obtained from specifying $u(c)$ such that $u^{\prime \prime \prime}()>0$ is offset by the reference-dependent component of utility. With $\alpha=2$, the third derivative of $v(c \mid \xi)$ is zero but the Kimball (1990) index of absolute prudence is smaller than it would be in the absence of RDU. ${ }^{3}$ So, unless $\alpha>2$, household preferences are restricted to display less sensitivity to the location of risk at very low levels of consumption in the presence of RDU and loss aversion than would be the case under a standard utility specification. We conclude that if a lower partial moment is used to measure downside risk, then a moment of order greater than 2 should be used.

Breitmeyer, Hakenes et al. (2004) note the similarity of LPM risk measures to poverty indices. They argue that many of the axioms required of the latter are also desirable for risk measures and, consequently, that suitably translated poverty indices are appropriate downside risk measures. For example, one can obtain DRM analogous to the Foster, Greer et al. (1984) class of poverty indices simply by normalizing the LPM measures on the threshold,

$$
\operatorname{DRM}_{\alpha}^{F G T}\left(F_{C} ; \xi\right)=\frac{1}{\xi^{\alpha}} \int_{0}^{\xi}(\xi-c)^{\alpha} d F_{C}=\int_{0}^{\xi}\left(1-\frac{c}{\xi}\right)^{\alpha} d F_{C}
$$

The normalization places these indices on the unit interval, which the LPM measures are not - their upper bound is the threshold to the power $\alpha$. Keeping in mind that these indices measure risk faced by a given household and the thresholds can be household-specific, for aggregation and comparison it is useful to have indices on the unit interval. Otherwise, there is nothing to choose between the LPM and FGT measures. They imply the same risk preferences.

\section{Downside risk with loss defined in utility units}

Rather than use a LPM based risk measure with $\alpha>2$, plausible higher order risk preferences can be obtained by specifying RDU with the loss defined not in monetary units $(\max (0, \xi-c))$ but in terms of

term is not smaller than that of the second. With RDU, $\partial A R A / \partial c=\left(-u^{\prime \prime}(c) / u^{\prime}(c)+1\right)+A R A^{2}$ and the condition is less likely to hold. For example, if pure consumption utility displays constant absolute risk aversion, then in the presence of RDU there will be increasing absolute risk aversion preferences below the threshold.

${ }^{3}$ Kimball's (1990) absolute prudence measure is $-U^{\prime \prime \prime} / U^{\prime \prime}$. With $\alpha=2$, it is $\frac{-u^{\prime \prime}}{\left(u^{\prime \prime}-2(\xi-c)^{\alpha-2}\right)}$, which, at any given

level of consumption, is less than it would be in the absence of RDU i.e. $\frac{-u^{\prime \prime}}{u^{\prime \prime}}$. 
unrealised satisfaction. This achieves consistency between the specification of the pure consumption and reference-dependent components of utility (Sugden 2003; Kőszegi and Rabin 2006). We have,

$$
U(c \mid \xi)= \begin{cases}u(c) & \text { if } c \geq \xi \\ u(c)+\varphi(u(c)-u(\xi)) & \text { if } c<\xi\end{cases}
$$

The function $\varphi($ ) represents the nature and magnitude of loss aversion. We choose the identity function. This has two important implications. First, the Köbberling-Wakker index of loss aversion (Köbberling and Wakker 2005) is 2, which is close to the original experiment-based estimate of Kahneman and Tversky (1979) and to other estimates obtained from both experimental studies (Abdellaoui, Bleichrodt et al. 2007) and structural econometric analysis (Tovar 2009). ${ }^{4}$ Second, with $u($. concave, utility is concave below, as well as above, the threshold ensuring increasing sensitivity to losses. As argued above, while this departs from the standard assumption of prospect theory, we believe that it is appropriate when measuring exposure to catastrophic losses.

We specify $u($.$) to be isoelastic as follows,$

$$
u(c)=\left\{\begin{array}{lll}
\frac{1}{1-\rho} c^{1-\rho} & \text { for } & \rho \geq 0, \rho \neq 1 \\
\ln c & \text { for } & \rho=1
\end{array}\right.
$$

With this specification, both above and below the threshold there is i) decreasing absolute risk aversion $(A R A=\rho / c)$, ii) constant relative risk aversion with a coefficient of $\rho$, iii) prudence (downside risk aversion), and iv) decreasing absolute prudence, with an index of $(1+\rho) / c$. This specification allows for loss aversion while not imposing that either risk aversion (RA) or downside risk aversion (DRA) below the threshold is less than it would be in the absence of RDU. RA and DRA are no greater than they would be in the absence of a reference dependent component of utility but this is not necessarily a limitation since the loss aversion parameter captures the inflated aversion to downside risk.

When $\rho=1$, the downside risk measure is ${ }^{5}$,

$$
D R M_{1}\left(F_{C} ; \xi\right)=\int_{0}^{\xi}(\ln (\xi)-\ln (c)) d F_{C}
$$

\footnotetext{
4 The Köbberling-Wakker index is $\frac{U_{\uparrow}^{\prime}(\xi)}{U_{\downarrow}^{\prime}(\xi)}=\frac{2 u^{\prime}(\xi)}{u^{\prime}(\xi)}=2$ where the numerator and denominator of the first term are the left and right derivatives of utility respectively at the threshold.

5 This index is not defined at $c=0$. In the application presented below we censor medical expenditures at $99 \%$ of income in order that non-medical consumption can never be zero.
} 
This measure is analogous to the Watts (1968) index of poverty. The latter is obtained with $\xi$ defined as the poverty line and integration over the distribution of household incomes and not the distribution of consumption faced by a single household. If the distribution of non-medical consumption lies entirely above the threshold, then the index is zero. If the distribution has support below the threshold but is degenerate at the lowest possible value of $c$ (assumed to equal one), then the index is $F_{C}(\xi) \ln \xi$.

Dividing through by $\ln \xi$ gives a normalised risk measure with a maximum value of $F_{C}(\xi)$,

$$
\operatorname{DRM}_{1}^{N}\left(F_{C} ; \xi\right)=\int_{0}^{\xi}\left(1-\frac{\ln (c)}{\ln (\xi)}\right) d F_{C}
$$

This normalisation, which is analogous to the Hagenaars (1987) poverty index, is more convenient for purposes of comparison. It does not affect risk preferences below the threshold but it is likely to reduce the degree of loss aversion. The Köbberling-Wakker index of loss aversion is $(1+1 / \ln \xi)$. So, for any $\xi>2.7183$ the loss aversion parameter is less than 2 .

For $\rho \neq 1$, the downside risk measure is,

$$
D R M_{\rho}\left(F_{C} ; \xi\right)=\frac{1}{1-\rho} \int_{0}^{\xi}\left(\xi^{1-\rho}-c^{1-\rho}\right) d F_{C}
$$

\section{Decomposition}

When $\varphi($.$) is specified as the identity function, the downside risk measure can be written as, { }^{6}$

$$
\operatorname{DRM}\left(F_{C} ; \xi\right)=\int_{0}^{\xi}(u(\xi)-u(c)) d F_{C}
$$

This decomposes into the probability that consumption falls below the reference point $\left(F_{C}(\xi)\right)$ and the expectation of the feeling of loss if it does so,

$$
\operatorname{DRM}\left(F_{C} ; \xi\right)=F_{C}(\xi)\left\{u(\xi)-\int_{0}^{\xi} \frac{u(c) f(c)}{F_{C}(\xi)} d c\right\}=F_{C}(\xi)\{u(\xi)-E[u(C) \mid C<\xi]\}
$$

The conditional expectation of the sensation of loss can be further decomposed into the anticipated loss due to the predictably low level of consumption if it does fall below the threshold $\left(L_{P}\right)$ and the loss due to the risk faced below the threshold $\left(L_{V}\right)$,

$$
\begin{aligned}
\operatorname{DRM}\left(F_{C} ; \xi\right) & =F_{C}(\xi)\{[u(\xi)-u(E[C \mid C<\xi])]+[u(E[C \mid C<\xi])-E[u(C) \mid C<\xi]]\} \\
& =F_{C}(\xi)\left\{L_{P}+L_{V}\right\} .
\end{aligned}
$$

\footnotetext{
${ }^{6}$ To obtain the normalised index with $\rho=1$, one obviously needs to divide through by $\ln \xi$.
} 
Provided $u(c)$ is concave, $L_{V}>0$ and represents the loss of satisfaction due to the volatility of consumption around its expected level below $\xi$. If $u(c)$ is specified as logarithmic, then $L_{V}$ corresponds to the mean logarithmic deviation index which is part of the family of generalised entropy indices of inequality. ${ }^{7}$ Under this specification and using the approximation $\ln (1+\mathrm{g}) \approx \mathrm{g}$, the term $L_{P}$ can be interpreted as the proportionate deficit of expected consumption below the threshold. ${ }^{8}$

\section{Downside risk without loss aversion}

Above we derived downside risk measures for medical expenditure from a model of reference-dependent utility that makes the threshold against which risks are evaluated internal to preferences. The household experiences a loss when medical expenses prevent threshold consumption from being reached. There is loss aversion. We believe that this is the correct approach when the aim is to capture the welfare loss from exposure to catastrophic medical expenditure risk. An alternative approach views the threshold not as part of preferences but as an ad hoc benchmark imposed by the evaluator. This is analogous to the measurement of poverty relative to a poverty line. The threshold is assumed to be meaningful from a societal perspective, but not necessarily that of the household.

The same DRM can be derived from this approach but they have a different interpretation. Assuming the household experiences no loss aversion, the measures must now be interpreted as indicating the household's expected deficit of utility relative to the level that would be realised if consumption were to reach the threshold. The utility function under this interpretation is: i) $\xi^{\alpha}-\left[\max (0, \xi-c)^{\alpha}\right]$ for $D R M_{\alpha}^{j}\left(F_{C} ; \xi\right), j=L P M, F G T$, ii) $\ln c$ for $D R M_{1}\left(F_{C} ; \xi\right)$ and, iii) $\frac{1}{1-\rho} c^{1-\rho}$ for $D R M_{\rho}\left(F_{C} ; \xi\right), \rho>1$ Only the LPM-based measures imply a kink in utility at the threshold. But utility function i) implies: a) risk loving behaviour below the threshold unless $\alpha \geq 1$ (Fishburn 1977), b) downside risk aversion only if $\alpha>2$, and c) increasing absolute risk aversion for $\alpha>1$. The risk preferences implied by the power function specifications are more plausible but utilising these within a downside risk measure imposes an inconsistency. While the household's utility is not evaluated relative to a threshold, its exposure to risk is.

\section{Specification of the threshold}

Choice of an appropriate threshold depends upon the interpretation to be placed on the risk measure. Interpretation within the context of RDU preferences requires that the threshold be meaningful to the household. The most obvious choice is the expectation, which is the specification made in models of

\footnotetext{
7 A similar decomposition has been used by Chakravarty, Deutsch and Silber (2008) to decompose the Watts poverty index into (1) the headcount ratio of poverty, (2) the percentage gap between the poverty line and the mean income of the poor and (3) the Bourguignon-Theil index of income inequality among the poor.
}

${ }^{8}$ Given $L_{P}=\ln \left(\frac{\xi}{E[C \mid C<\xi]}\right)$ and $\xi>\mathbf{E}[\mathbf{C} \mid \mathbf{C}<\xi]$, we can define $g=\frac{\xi}{E[C \mid C \leq \xi]}-1$ 
disappointment aversion (Bell 1985; Loomes and Sugden 1986). The household forms an expectation of its expenditure on health care and, given assumed knowledge of its income and ability to finance medical care, its non-medical consumption in the next period. If medical expenditure turns out to be higher than expected, then there will be a feeling of disappointment that consumption cannot reach the level anticipated. Exposure to the risk of frustrated expectations is measured.

While this is undoubtedly a meaningful risk, one should be aware of what it does not capture. First, disappointment from consumption being less than expected is quite different from devastation following a sudden and serious illness requiring expensive treatment that leaves consumption not only a little below its expectation but at a desperately low and unanticipated level. The risk of spending more on health care than expected is not the same as the risk of incurring catastrophic payments with dramatic consequences for living standards. But exposure to such catastrophic risk is not overlooked when the threshold is set equal to the expectation. The DRM is sensitive to all of the distribution of consumption below the threshold. Provided the loss function is concave, then greater weight is placed on marginal losses further below the threshold. Two households that faced distributions with equal density below their respective expectations but that differ in the density at the left tail of the distribution will be discriminated.

Greater focus on truly catastrophic health payments could be achieved by locating the threshold above the expected value of payments, $\zeta=E[\tilde{M}](1+\eta)+\kappa, \eta \geq 0, \kappa \geq 0 .{ }^{9}$ For example, by specifying $\eta=0, \kappa=\sigma_{\tilde{M}}$, where $\sigma_{\tilde{M}}$ is the standard deviation, one is measuring exposure to the risk of spending more than a mean (squared) deviation from the expected value. This ensures measurement of exposure to the truly least expected outcomes but it means that the catastrophic payments threshold is higher for households facing both greater expected and more variable payments. This could result in lower measured risk exposure for distributions of higher variance. Further, making the threshold a purely additive function of the expectation $(\eta=0)$ is unappealing. Spending $\$ 1000$ more than expected is surely a greater catastrophe when one expected to spend $\$ 100$, than when one expected to spend $\$ 10,000$. If the threshold is to be raised above the expected value, then a multiplicative function seems preferable. But it is difficult to reconcile any such threshold with preferences. Why should there be a sense of loss when payments for health care are, say, $20 \%$ more than expected but no such sensation when payments exceed expectations by $19 \%$ ? If one is to interpret the risk measure within the context of a RDU model, then the expected value seems the most internally consistent and least arbitrary choice of threshold. Sufficient sensitivity of the risk measure to catastrophic health payments can then be achieved through a sufficiently concave loss function.

Setting the threshold equal to the mean gives paradoxical results when risk is measured exclusively by the zero order lower partial moment. This measure is 0.5 when the distribution is symmetric. It will be

\footnotetext{
${ }^{9}$ Restrictions must be imposed on the parameters $\eta$ and $\varkappa$ to ensure the threshold does not exceed the upper bound on the distribution of $\tilde{M}(E[\tilde{M}](1+\eta)+\kappa \leq \tilde{y})$ and so the integrals in (4) and the other DRM are defined.
} 
smaller the more right-skewed is the distribution of medical expenditures, and so the more left-skewed is the distribution of non-medical consumption. It would be strange to conclude that households facing a distribution more skewed toward very high health payments are less exposed to risk. Reliance on the zero order lower partial moment is unattractive because of its sensitivity to the threshold but not the distribution below the threshold. Used exclusively, it is a particularly unsuitable risk measure when the threshold is the expected value.

Setting the threshold at the expected value does mean that it is a household's exposure to medical expenditure risks that is being measured and not the burden of those expenditures. A household facing predictably high OOP payment for continuous medication of a chronic disease will not necessarily be identified as at risk of incurring catastrophic expenditure. This is not a problem provided the aim is to measure risk; in order to identify households that can benefit most from insurance, for example. Subsidisation, rather than insurance, is required to compensate households with predictably high medical expenditures. Identification of these households does not require a measure of risk. Rather, regression analysis can be used to identify how the expected value of OOP payments varies with observable characteristics, such as chronic disease.

If one moves away from the RDU interpretation of downside risk measures, then the threshold can be defined in relation to societal goals, rather than household preferences. Setting the threshold equal to the poverty line gives measures of the household's vulnerability to poverty assessed on the basis of nonmedical consumption. But this would not distinguish between poverty generated by a low budget and poverty due to high health expenditures. Nor would it measure exposure to catastrophic risk in a household that faces a high risk of large health payments but whose income is sufficiently high such that there is little risk of falling below the poverty threshold.

The argument for setting the threshold in relation to income, as has been done in the measurement of catastrophic payments until now, is stronger. In the presence of administrative costs, which are likely to be high in developing countries, the optimal insurance has a deductible (Arrow 1971). Moral hazard creates a further argument for covering large losses but not small ones (Blomqvist 1997). In the US context, Martin Feldstein has been a long-standing advocate of major risk health insurance consisting of a $50 \%$ coinsurance rate combined with a ceiling on OOP payments at 10\% of income (Feldstein 1971; Feldstein and Gruber 1995). The idea is to constrain moral hazard while limiting risk exposure in the part of the income distribution where risk aversion is likely to be greatest. Gruber (2006) finds further rationale for an income-related ceiling in the RAND Health Insurance Experiment, which found that copayments reduced health care utilisation but only with some indication of negative consequences for health among lower income individuals with chronic health problems (Newhouse 1993). An incomerelated deductible reduces the likelihood that poor individuals most in need of health care will forgo effective treatments. In the context of low and middle income countries, a strong access motive for health insurance (Nyman 1999) makes moral hazard less of a concern but tight resource constraints, small 
formal employment sectors and high administration costs make it likely that insurance coverage will remain limited. Notwithstanding the difficulties of implementation, the arguments for an income-related deductible then have at least as much force as they do in a rich country like the US.

Setting the threshold of a downside risk measure at some fraction of income allows one to identify the households at greatest risk of being confronted with medical expenses in excess of that share of income, who would benefit most from (subsidised) catastrophic health insurance coverage. In the application presented below we use thresholds defined both in relation to expected medical expenditures and income.

\section{Simulation of Consumption Distribution}

Implementation of the downside risk measures introduced in the previous section requires estimation of the distribution of non-medical consumption faced by the household, and specification of both a satisfaction function and a threshold. The distribution of consumption is retrieved from the household's income and its distribution of OOP health payments not financed from coping strategies using, $C=\tilde{y}-(1-\theta) M$. We simulate the distribution of health payments not financed from coping strategies by modelling all OOP payments conditional on their sources of finance and predicting under the counterfactual of no financing other than from current income.

It would be preferable to estimate the distribution of OOP payments from a long series of panel data on medical expenditures but this is seldom available, particularly in developing countries. Relying on crosssection data requires assuming that the through time variability in medical expenditures faced by a household is equal to the point-in-time variability across households with the same observable characteristics. This requires that medical expenditures are generated by a stationary ergodic process and are identically and independently distributed across both time and households ${ }^{10}$. While these are strong assumptions, they are implicit in the many studies that estimate risk premia from cross-section data (Feldstein and Gruber 1995; Finkelstein and McKnight 2008; Pauly, Blavin et al. 2009; Engelhardt and Gruber 2011).

Given that a large proportion of households make no payments for health care within the survey period, we model a type of two-part model (Duan, Manning et al. 1983). Define,

$$
\begin{array}{r}
\pi=P\left(M>0 \mid Z_{1}\right) \\
1-\pi=P\left(M=0 \mid Z_{1}\right)
\end{array}
$$

where $Z_{1}$ are covariates. Conditional on $M>0, M$ has a continuous distribution with density,

$$
f_{1}\left(m \mid Z_{2}\right)=f\left(m \mid m>0, Z_{2}\right)
$$

\footnotetext{
${ }^{10}$ Ergodicity implies that the time series average of the distribution of a household converges towards the same limit as the average over households at a given point in time, $E\left[M_{i}\right]=E\left[M_{t}\right]=\mu$.
} 
The unconditional distribution is semi-continuous with a discontinuity at zero,

$$
f(m \mid Z)=(1-\pi) \delta(m)+\pi f_{1}\left(m \mid Z_{2}\right) 1(m>0)
$$

where $\delta(m)$ is a point probability mass ${ }^{11}$ and $1(m>0)$ is the indicator function. This mixture density is consistent with a two-part model in which the parameters of the probability of non-zero expenditures can be estimated separately from those of the conditional (on positives) distribution. We estimate the first part by probit, $\pi_{i}=\Phi\left(Z_{1 i} \gamma_{1}\right)$ where $\Phi($.$) is the standard normal cumulative distribution function and$ we now include the index $i$ to make clear that an estimate of the probability is obtained for each household.

The conditional (on positives) density is estimated by quantile regressions (Engelhardt and Gruber 2011). We specify the quantiles of the $\log$ of $M$ as linear in covariates,

$$
Q_{\ln m}\left(q \mid m_{i}>0, Z_{2 i}\right)=Z_{2 i} \gamma_{2}(q)
$$

where $Q($.) is the conditional quantile function and $q$ is a quantile. Given quantiles are order statistics that are invariant to monotonic transformations, there is no retransformation problem introduced by specifying the conditional quantile function as log-linear rather than linear (Cook and Manning 2009). Exponential transformation of the conditional quantile on the log scale corresponds to the inverse of a point on the cumulative distribution function on the raw scale:

$$
\begin{aligned}
\exp \left[Q_{\ln m}\left(q \mid m_{i}>0, Z_{2 i}\right)\right] & =\exp \left[\ln \left(Q_{m}\left(q \mid m_{i}>0, Z_{2 i}\right)\right)\right] \\
= & Q_{m}\left(q \mid m_{i}>0, Z_{2 i}\right)=F_{M}^{-1}\left(q \mid m_{i}>0, Z_{2 i}\right)
\end{aligned}
$$

Estimating the conditional (on positives and covariates) quantile function at many quantile points allows one to estimate the conditional cdf of positive OOP health payments. However, it is the distribution of OOP payments financed from income and not from coping strategies that we need. That is, we want $F_{\tilde{M}}$ not $F_{M}$. To obtain this we use the information in the data on the sources used to finance OOP payments (see next section). Each household is asked if they financed any OOP health payments from current income, savings, sale of assets, transfers from friends/relatives, borrowing and other sources. This allows us to specify the conditional quantile function (17) more explicitly as,

$$
Q_{\ln m}\left(q \mid m_{i}>0, I_{i}, \mathbf{D}_{i}, \mathbf{X}_{i}\right)=\alpha(q) I_{i}+\sum_{k=1}^{K} \psi_{k}(q) D_{k i}+\mathbf{X}_{i} \vartheta(q)
$$

where $I_{i}$ is an indicator of whether the household reports financing health expenditures from current income and $D_{k i}$ indicates financing from the $k^{\text {th }}$ coping strategy (i.e. savings, borrowing, etc.). When predicting OOP payments we set $D_{k i}=0 \forall k$ in order to simulate the distribution of medical

\footnotetext{
11 This is the Dirac delta function, a cumulative distribution function which jumps from 0 to 1 at the point $m=0$.
} 
expenditures that are not financed from informal insurance. The dependent variable is defined as payments for health care net of any reimbursement from formal health insurance. Since one expects coping strategies to be deployed to finance the largest medical costs, the simulated distribution will be denser than that which would be generated if all sources of finance were permitted. This is as it should be since we are aiming to identify the immediate risk to non-medical consumption. In the longer run, borrowing etc. to pay for health care may threaten the living standard of the household. This should not be overlooked but taking it into account would require moving beyond the static approach we have adopted.

We estimate (19) at q=0.01, 0.02,...,0.99 and from each predict at $\mathbf{D}_{i}=0$ and apply the exponential transformation to give estimates of 99 quantiles on the conditional (on positives) distribution of OOP payments not financed from any coping strategy. To recover the unconditional distribution, we use the fact that $q^{\prime}=(1-\pi)+\pi q$, where $q^{\prime}$ is the quantile of the distribution over both zero and positive values. The 99 points on the conditional distribution are supplemented with $n_{0 i}=\frac{\left(1-\pi_{i}\right)}{\pi_{i}} 99$ zero values. This gives $n_{i}=n_{0 i}+99$ points on the unconditional distribution from which there is a probability of $\left(1-\pi_{i}\right)=n_{0 i} / n_{i}$ of drawing a zero value and a probability of $\pi_{i} / 99$ of drawing any one of the positive values. For each household, we take 99 random draws with replacement from these observations to simulate the distribution of uninsured OOP health payments.

In order to get from the distribution of OOP payments to that of non-medical consumption, we need to estimate the household's income, which is not reported in the survey used. Total expenditure cannot be used since this will include expenditures on medical care that are financed from coping strategies. We therefore model the expectation of total household expenditure and predict conditional on OOP payments not being financed from these sources. The conditional expectation of total spending is specified as,

$$
E\left(y_{i} \mid I_{i}, \mathbf{D}_{i}, \mathbf{X}_{i}\right)=\exp \left(\varsigma I_{i}+\sum_{k=1}^{K} \lambda_{k} D_{k i}+\mathbf{X}_{i} \omega\right)
$$

with the error of this Generalised Linear Model (GLM) assumed to follow a gamma distribution. Predicting with $D_{k i}=0 \forall k$ provides an estimate of $\tilde{y}_{i}$. It is the conditional expectation of the consumption that can be achieved while leaving net worth unchanged. Each draw from the household's simulated marginal distribution of OOP payments is subtracted from this predicted total expenditure to give the simulated distribution of non-medical consumption, the variance of which is generated by payments for medical care that the household is unable to finance from saving, borrowing, selling assets, or any other source that shields consumption. Measures derived from this distribution capture the 
household's exposure to risk remaining after the exercise of all formal, informal and self insurance options.

It is possible that a draw from the OOP distribution exceeds predicted income. We therefore censor the OOP distribution at $99 \%$ of predicted income. ${ }^{12}$

\section{DATA}

We illustrate the risk measures and simulation method using data from the World Health Surveys (WHS), which were conducted by the World Health Organization in 2002-2003.13 We use data for seven Asian countries: Bangladesh, India, Pakistan, China, Laos, Malaysia and the Philippines. Multiple countries are examined in order to explore patterns in the properties and correlates of the risk measures and also to demonstrate the potential of the approach for cross-country comparison of medical expenditure risk. The samples are nationally representative for all countries except India and China. In India, the sample is representative for six purposively selected major states that account for $47 \%$ of the total Indian population (Arokiasamy, Guruswamy et al. 2006). ${ }^{14}$ In China, sampling was conducted in nine provinces accounting for $41 \%$ of the country population but the sample is rather small at less than 4000 households (see Table A2). ${ }^{15}$ We focus on the results obtained from the Philippines sample, which is the largest at 9035 households, and use the others for cross-country comparisons.

\section{Expenditure data}

In addition to collecting data on health status and health care, the WHS also asked about household spending on health care and total household expenditure. Spending on health care is reported in more detail than spending on other items, which, together with the general health focus of the survey, results in estimates of medical expenditure budget shares that are higher than those obtained from expenditure surveys. While this is clearly a limitation with respect to estimation of the impact of health spending on non-medical consumption and consequently medical expenditure induced risk, we nonetheless favour the WHS data since they are unparalleled in the consistency of the information provided on health and health spending across countries. In addition, they provide information on the sources of financing health care, which, as explained in the previous section, is valuable in taking account of informal insurance.

The household respondent is asked how much the household spent in total in the last four weeks on: i) food, ii) housing, utilities and heating, iii) education, iv) health care (excluding expenses reimbursed by

\footnotetext{
12 The proportion of households with at least one censored value of OOP varies from 0.2 in Malaysia to 0.87 in Laos. Conditional on there being any censoring, on average, 1.4 of the 99 draws from the simulated OOP distribution are censored in Malaysia and 4.7 are censored in Laos.

13 See http://www.who.int/healthinfo/survey/en/

14 The six states (Assam, Karnataka, Maharashtra, Rajasthan, Uttar Pradesh and West Bengal) were selected by stratifying all states by region and an index of level of development and selected one state from each strata. The samples are representative to each of the states and for the six states jointly (Arokiasamy et al, 2006).

15 The nine provinces covered are Jiangsu, Guangdong, Shanxi, Zhejiang, Hebei, Hubei, Sichuan, Gansu and Shaanxi.
} 
insurance), v) voluntary insurance premiums, and vi) all other goods and services. The amount paid for all overnight stays in hospital over the last 12 months (excluding that already reported in iv)) is also recorded. The different recall period for spending on inpatient care creates a common problem in the estimation of aggregate medical expenditure. We choose to multiply the four week expenditure by 13 and add it to the amount spent on inpatient care to get annual medical expenditure. Multiplication by a constant affects the location of the distribution but it does not alter its dispersion or shape, which is important in the present context. When data on item iv) is missing, we substitute with information from more detailed questions on spending on specific types of health care and medicines. Total annual household expenditure is calculated by multiplying the sum of items i)-iii) and v)-vi) by 13 and adding this to the computed spending on health care. The means of these two variables by country are presented in Appendix Table A2.

\section{Covariates}

The covariates used to predict both medical and total expenditure include the sources used to finance health care, health indicators, ownership of assets/durables, housing conditions correlated with health risks, education, mandatory health insurance coverage (China and Malaysia only), household demographics, ethnicity, urban/rural location and region fixed effects. The complete list is given in Appendix Table A1 and means are given in Table A2. The location, scale and shape of the distribution of medical expenditures are allowed to vary with each covariate.

The respondent is asked whether the household used each source from an itemised list to pay for health care in the last 12 months. The list includes: current income, savings, reimbursement from health insurance, sale of items, transfers from family members or friends, borrowing (other than from family and friends) and any other source. We construct a dummy indicator for each one of these sources with the exception of insurance. ${ }^{16}$ These correspond to the $I$ and $D_{k}$ indicators included in equations (19) and (20).

The health information used to predict medical (and total) expenditures takes the form of indicators of five non-communicable diseases - arthritis, angina, asthma, depression and diabetes. The main respondent is asked a series of questions concerning possible symptoms of the first four of these conditions that may have been experienced in the last 12 months, as well as whether a diagnosis has been made. Moussavi et al (2007) derived optimal algorithms for the detection of each condition from these questions using Receiver Operating Characteristic (ROC) analyses on the basis of a diagnostic item probability study conducted in seven countries. We use these algorithms to define indicators of the four conditions. For diabetes, only diagnosis is available. In addition, we use an indicator of any reported problem affecting the mouth or teeth (oral). These health indicators are available only for one household member selected randomly. The missing health information on other household members means that we will

16 In reporting health payments, respondents are instructed not to report expenditures that were reimbursed from insurance. 
underestimate the variation in spending on health care that is predictable to the household given its health status. Risk will be overestimated.

We deliberately condition only on indicators of chronic health problems. The intention is to capture variation in medical expenditure which is predictable given health conditions that exist at the beginning of any period. Acute illnesses are deliberately left 'unobservable' and will generate variation across households with the same control variables. This unpredicted variation represents risk. A household that experiences an acute illness during the survey recall period will presumably end up at a high quantile of the conditional distribution of expenditures, while another that is unusually healthy in that period will be located at a low quantile. The propensity and severity of acute sickness may vary with the presence or absence of a particular chronic illness. In that case, the impact of chronic conditions will differ across quantiles and the dispersion (as well as the location) of the medical expenditure distribution will vary with those conditions. Control is made for whether a child under the age of five has received the DPT or measles vaccination, or has received vitamin A supplement (preventive). The intention is to control for preventive behaviour that may reduce exposure to health expenditure risks arising from acute sickness of children.

We condition on a battery of durables e.g. fridge, radio, TV, etc. intended to proxy wealth (see Table A1). In doing so we make the distribution of medical expenses the household is predicted to face depend on its ability to pay. This is necessary if a budget constraint is to be respected. Poor households do not face a risk of incurring medical costs of millions of dollars. We are estimating exposure to risks of medical expenditures that can be afforded, albeit with duress, not to risks of needing medical care that is unaffordable. Housing materials, quality of water supply and sanitation (see Table A1) are used both as further proxies for ability to pay and to represent health risk factors that may affect the distribution of medical expenses. Household demographics are represented by the log of household size and the proportion of members in various age-sex categories (Table A1).

\section{RESULTS}

We estimate all the risk measures discussed in section 2. After illustrating similarities and differences between them, we concentrate on our favoured measure -the CRRA downside risk measure, $D R M_{\rho}$. We compute this measure for $\rho=1,2 \& 3$, which spans the central tendency estimate of the coefficient of relative risk aversion of around 2 found in the literature (Meyer and Meyer 2005).

We compute the risk measures at thresholds defined in relation to both expected consumption and income. Specifically, we use three thresholds: expected consumption, $80 \%$ of expected consumption and $80 \%$ of income. Under the assumptions made and the simulation method adopted, the risk of consumption falling below its expected value corresponds to that of medical expenditure exceeding its expected value. To capture exposure to catastrophic risks, as opposed to the risk of being disappointed 
that consumption does not turn out to be as high as expected, we use the threshold of $80 \%$ of expected consumption. ${ }^{17} \mathrm{~A}$ threshold set as a proportion $(80 \%)$ of income is used for the reasons given at the end of section 2. Consumption will fall below $80 \%$ of income if medical expenditure is more than $20 \%$ of income, which corresponds to one of the thresholds commonly used in the literature on catastrophic health payments. This threshold will be lower than expected consumption provided expected medical expenditure is less than $20 \%$ of income, which seems likely. The threshold of $80 \%$ of income is necessarily greater than $80 \%$ of expected consumption. ${ }^{18}$ So, it is likely that the ordering of the thresholds is: $E[c]>80 \% \tilde{y}>80 \% E[c]$. On average across households, this is true for all the countries analysed.

\section{Regression estimates}

Estimates of the GLM of total household expenditure per capita (eqn. 20) and of a two-part model of medical expenditure per capita for the Philippines are presented in Table 1. The second part of the latter model - a GLM (gamma family and log link) - is not used in the simulation of the medical expenditure distribution. It is presented to give an impression of how medical expenditures vary with covariates, which cannot be done for the full 99 quantile regression estimates used in the simulation. Estimates are presented for the covariates indicating the financing of medical expenditures, health, education, urban and household size. The joint significance (by group) of the remaining covariates is indicated. Coefficients from the GLMs are presented. Since the link function is specified to be logarithmic, the coefficients correspond to semi-elasticities. The log of household size is entered in the models and so the respective coefficients are elasticities.

Households that report paying for health care and medicines through savings, asset sales, receipt of transfers and any other source of finance besides income have higher total expenditures. ${ }^{19}$ For example, average expenditure is $8.6 \%$ higher in households that finance medical care from savings. We interpret these positive correlations as reflecting the exercise of coping strategies to pay for health care while, at least partially, protecting non-medical consumption, resulting in an increase in total household expenditure. This is consistent with evidence indicating that households are able to at least partially smooth consumption over health shocks in low and middle income countries (Genoni 2012; Islam and Maitra 2012; Mohanan forthcoming; Townsend 1994), while being unable to fully shield consumption (Dercon and Krishnan 2000; Gertler and Gruber 2002; Asfaw and von Braun 2004). Another explanation is that better off households have greater reserves of savings, assets, etc. to draw on in times of need. In this case, the coefficients on the financing sources partly reflect the cross-sectional variation in possession of savings, assets, etc. While we cannot rule out this potential bias, the risk that it exists is weakened by

\footnotetext{
17 This corresponds to medical expenditure exceeding the sum of $80 \%$ of mean medical expenditure and $20 \%$ of income, since: $c<k E[c] \Leftrightarrow(\tilde{y}-m)<k(\tilde{y}-E[m]) \Leftrightarrow m>\tilde{y}(1-k)+k E[m]$.

$18 k \tilde{y}-k E[c]=k \tilde{y}-k(\tilde{y}-E[m])=k E[m]>0$

${ }^{19}$ For the Philippines, borrowing is included in 'other finance' since relatively few households report resorting to this.
} 
the fact that we control for a very extensive list of household durables and housing conditions, as well as education and location, which should do a good job in controlling for variation in wealth.

Table 1: Conditional mean function of total expenditure (totexp) and 2-part model of medical expenditure (OOP) for the Philippines

\begin{tabular}{|c|c|c|c|c|c|c|}
\hline \multirow{3}{*}{ Source of OOP financ } & \multicolumn{2}{|c|}{ E[totexp] - GLM } & \multicolumn{2}{|c|}{$\operatorname{Pr}(\mathrm{OOP}>0)$ - Probit } & \multicolumn{2}{|c|}{$\mathrm{E}[\mathrm{OOP} \mid \mathrm{OOP}>0]-\mathrm{GLM}$} \\
\hline & $\begin{array}{l}\text { (semi) } \\
\text { elasticity }\end{array}$ & $\begin{array}{c}\text { Robust } \\
\text { SE }\end{array}$ & Partial effect & $\begin{array}{c}\text { Robust } \\
\text { SE }\end{array}$ & $\begin{array}{c}\text { (semi) } \\
\text { elasticity }\end{array}$ & $\begin{array}{c}\text { Robust } \\
\text { SE }\end{array}$ \\
\hline & & & & & & \\
\hline current income & 0.0265 & $(0.0178)$ & & & $-0.153 * *$ & $(0.0712)$ \\
\hline savings & $0.0859 * * *$ & $(0.0202)$ & & & $0.348 * * *$ & $(0.0582)$ \\
\hline sold assets & $0.157 * * *$ & $(0.0395)$ & & & $0.422 * * *$ & $(0.106)$ \\
\hline transfers & $0.107 * * *$ & $(0.0206)$ & & & $0.642 * * *$ & $(0.0628)$ \\
\hline other finance & $0.0561 *$ & $(0.0288)$ & & & $0.406 * * *$ & $(0.0722)$ \\
\hline \multicolumn{7}{|l|}{ Health } \\
\hline arthritis & -0.00924 & $(0.0192)$ & $0.0401 * * *$ & $(0.0127)$ & -0.0999 & $(0.0646)$ \\
\hline angina & 0.00275 & $(0.0215)$ & $0.0521^{* * *}$ & $(0.0135)$ & $0.118 *$ & $(0.0693)$ \\
\hline asthma & -0.00917 & $(0.0253)$ & $0.0696 * * *$ & $(0.0158)$ & 0.109 & $(0.0693)$ \\
\hline depression & $0.163 * * *$ & $(0.0586)$ & $0.0640 * * *$ & $(0.0231)$ & $0.496 * * *$ & $(0.120)$ \\
\hline diabetes & $0.141 * * *$ & $(0.0531)$ & $0.0999 * * *$ & $(0.0320)$ & $0.578 * * *$ & $(0.133)$ \\
\hline oral & $0.0340 * *$ & $(0.0154)$ & $0.0290 * * *$ & $(0.0103)$ & 0.0577 & $(0.0553)$ \\
\hline preventive & -0.0310 & $(0.0219)$ & $0.0565^{* * *}$ & $(0.0155)$ & $-0.150 *$ & $(0.0886)$ \\
\hline \multicolumn{7}{|l|}{ Education } \\
\hline primary & $0.104 * * *$ & $(0.0350)$ & $0.0950 * * *$ & $(0.0207)$ & -0.167 & $(0.124)$ \\
\hline secondary & $0.183 * * *$ & $(0.0349)$ & $0.0743^{* * *}$ & $(0.0220)$ & -0.0649 & $(0.127)$ \\
\hline higher & $0.330 * * *$ & $(0.0457)$ & $0.106 * * *$ & $(0.0273)$ & 0.0209 & $(0.150)$ \\
\hline urban & 0.0226 & $(0.0187)$ & 0.00989 & $(0.0117)$ & $-0.170 * * *$ & $(0.0598)$ \\
\hline household size & $-0.579 * * *$ & $(0.0230)$ & $0.0261 * *$ & $(0.0132)$ & $-0.836 * * *$ & $(0.0679)$ \\
\hline constant & $9.925 * * *$ & $(0.139)$ & & & $9.307 * * *$ & $(0.313)$ \\
\hline $\mathrm{N}$ & 9035 & & 9035 & & 5265 & \\
\hline \multicolumn{7}{|c|}{ Tests of joint significance (p-values) } \\
\hline finance & \multicolumn{2}{|c|}{0.0000} & & \multicolumn{2}{|c|}{0.0000} \\
\hline health & \multicolumn{2}{|c|}{0.0003} & \multicolumn{2}{|c|}{0.0000} & \multicolumn{2}{|c|}{0.0000} \\
\hline durables & \multicolumn{2}{|c|}{0.0000} & \multicolumn{2}{|c|}{0.0000} & \multicolumn{2}{|c|}{0.0000} \\
\hline housing & \multicolumn{2}{|c|}{0.0000} & \multicolumn{2}{|c|}{0.1605} & \multicolumn{2}{|c|}{0.4544} \\
\hline agesex & \multicolumn{2}{|c|}{0.0001} & \multicolumn{2}{|c|}{0.0001} & \multicolumn{2}{|c|}{0.0000} \\
\hline region & \multicolumn{2}{|c|}{0.0000} & \multicolumn{2}{|c|}{0.0000} & \multicolumn{2}{|c|}{0.0000} \\
\hline
\end{tabular}

Notes: $* \mathrm{p}<0.1 * * \mathrm{p}<0.05^{* * *} \mathrm{p}<0.01$

GLM models are with gamma distribution and log link. Coefficients presented, which for indicator variables correspond to semi-elasticities. Log of household size used and so coefficient corresponds to elasticity. Average partial effects from probit. All models include indicators of household durables, housing condition/water source/sanitation, age-sex composition of household and region. See Appendix Table A1 for descriptions of all covariates and Table A2 for means. Tests of joint significance are conducted for: i) finance - indicators of sources of financing medical expenditures (income-other finance); ii) health - arthritis-preventive; iii) assets - indicators of ownership of durables; iv) housing - indicators of housing conditions/water source/sanitation; iv) agesex - age-sex composition of household; v) region - indicators of region.

Total expenditure is higher in households with a presence of depression, diabetes and oral health problems. Since diabetes is indicated by diagnosis alone, it is possible that the $14 \%$ higher expenditure among households with this disease is attributable to greater awareness of the condition among the better off. In addition to the source of financing health care and health status, education, durables, housing conditions, demographic composition and region are all significance determinants of total expenditure. 
Turning to the explanation of medical expenditures, all the health indicators are significantly positively correlated with the probability of incurring health care costs. Those households in which the survey respondent has symptoms or a diagnosis of arthritis are 4 percentage points more likely to pay something for health care. Those with a diagnosis of diabetes are 10 points more likely to spend on medical care or medicines. The more educated and larger households are more likely to incur medical expenditures. Only housing conditions are not significantly related to the probability of spending on health care.

Restricting attention to those with medical expenditures, the amount paid is lower for those that finance from current income and it is higher for all other sources of finance. This suggests that while smaller expenses can be financed from income, larger medical bills can only be afforded by drawing on savings, assets sales, etc.. The amount paid is 35\% higher for those financing from savings. It is $64 \%$ higher when transfers are obtained from friends and relatives to pay for health care. These magnitudes suggest that informal coping strategies play a very important role in the financing of medical care in the Philippines. Ignoring these sources of informal and self-insurance would lead one to greatly overestimate exposure to medical expenditure risk.

The amount of medical expenditures in the Philippines is significantly higher for those with angina, depression or diabetes, while it is lower for households with a child that has received the DPT or measles vaccination or has received vitamin A supplement. The latter is consistent with preventive measures reducing medical bills. Per capita medical expenditures are lower in urban areas and for larger households. The demographic composition of the household, its location and ownership of durables are all correlated with medical expenditures, while housing conditions are not. ${ }^{20}$

\section{Simulated distribution of consumption}

The distributions of OOP health payments and non-medical consumption faced by each household are simulated following the procedure described in section 3. To illustrate the importance of coping strategies, we present in Table 2 for all countries the ratio of mean total expenditure predicted under the counterfactual of no financing other than from current income to the mean of the prediction with the financing actually deployed. The same is done for predicted medical expenditure, in which case we present the average over all households of the expected spending of each household. For the Philippines, the mean of the ratio of total expenditure with no financing of medical spending through coping to that under actual financing is 0.95 . So, on average, financing of health care through coping mechanisms amounts to $5 \%$ of total expenditure. This percentage is lower only in Malaysia (3\%) and it is around 10\% in India.

\footnotetext{
${ }^{20}$ Regression estimates and all other results for the other countries are available on request.
} 
On average, in the Philippines, predicted medical expenditure without the exercise of coping strategies is $81 \%$ of expenditure predicted on the basis of the coping strategies actually deployed..$^{21}$ This suggests that almost $20 \%$ of medical expenditures are financed through coping mechanisms. Again, the Philippines is not extreme in this respect. The figure is over 20\% in India. It is less than $10 \%$ in Malaysia, which comes much closer to achieving universal coverage through a tax-financed national health service that accommodates almost three-quarters of all inpatient admissions and delivers over four-fifths of outpatient consultations at very low user fees (Chua and Cheah 2012). More surprisingly, it is also less than $10 \%$ in Laos, where public health care provision and formal insurance are extremely sparse. This suggests that households in Laos cannot protect consumption from medical expenditure risks through either formal or informal insurance mechanisms.

Table 2: Ratio of mean of predicted total (medical) expenditure under counterfactual of no financing of spending on medical care from coping strategies to mean prediction under actual financing

\begin{tabular}{lccccccc}
\hline & Bangladesh & India & Pakistan & China & Laos & Malaysia & Philippines \\
\hline Total household expenditure & 0.9381 & 0.9038 & 0.9168 & 0.9211 & 0.9139 & 0.9675 & 0.9470 \\
OOP medical expenditure & 0.8072 & 0.7943 & 0.8084 & 0.8789 & 0.9262 & 0.9150 & 0.8147 \\
\hline
\end{tabular}

Notes: Total expenditure predictions from GLM estimates. Medical expenditure predictions from probit and quantiles regression estimates. Mean medical expenditure is average across households of the expected value of each household. 'Coping stategies' refers to financing OOP medical expenditures from savings, borrowing, selling assets, transfers from friends/relatives or any other finance source other than current income.

\section{Comparison of risk measures}

Is the identification of households facing the greatest medical expenditure risk sensitive to the risk measure adopted? We address this question by examining Spearman rank correlation coefficients between the various risk measures calculated for the Philippines with the threshold set at each household's expected consumption (Table 3). All the downside risk measures are positively correlated with the exception of the zero order lower partial moment. The latter, which is the probability that consumption falls below its expected value, is positively correlated only with the first order lower partial moment and is negatively correlated with all other risk measures but for the second order LPM. This confirms our earlier warning that the probability of falling below the threshold is not a suitable risk measure when the threshold is defined as the expected value. Households that face more left-skewed distributions of consumption (right-skewed medical expenditures) will have greater downside risk exposure by most measures but will face a lower probability of dropping below expected consumption. If the threshold is set at $80 \%$ of income or $80 \%$ of expected consumption, then $L P M_{0}$ is no longer negatively correlated with most of the other risk measures. ${ }^{22}$

\footnotetext{
21 This refers to expected expenditure, not the mean amount of positive expenditures, and hence is not inconsistent with the estimated increase in the latter by $35-64 \%$ with reliance on certain coping mechanisms.

${ }^{22}$ For the same reason, the correlations between risk measures that depend on the probability of falling below the threshold increase when a threshold other than the expected value is used. Otherwise, the pattern of correlations
} 
Table 3: Spearman correlations between risk measures, threshold $=\mathrm{E}$ (consumption) the Philippines

\begin{tabular}{|c|c|c|c|c|c|c|c|c|c|}
\hline & $D R M_{0}^{L P M}$ & $D R M_{1}^{L P M}$ & $D R M_{2}^{L P M}$ & $D R M_{1}^{F G T}$ & $D R M_{2}^{F G T}$ & $D R M_{1}$ & $D R M_{1}^{N}$ & $D R M_{2}$ & $D R M_{3}$ \\
\hline$D R M_{1}^{L P M}$ & 0.1498 & 1.0000 & & & & & & & \\
\hline$D R M_{2}^{L P M}$ & $0.0102^{\dagger}$ & 0.9705 & 1.0000 & & & & & & \\
\hline$D R M_{1}^{F G T}$ & -0.0267 & 0.6750 & 0.6542 & 1.0000 & & & & & \\
\hline$D R M_{2}^{F G T}$ & -0.2637 & 0.5721 & 0.6408 & 0.9161 & 1.0000 & & & & \\
\hline$D R M_{1}$ & -0.1966 & 0.5854 & 0.6402 & 0.9201 & 0.9808 & 1.0000 & & & \\
\hline$D R M_{1}^{N}$ & -0.2143 & 0.5207 & 0.5768 & 0.9114 & 0.9786 & 0.9963 & 1.0000 & & \\
\hline$D R M_{2}$ & -0.3322 & 0.1499 & 0.2439 & 0.6853 & 0.8439 & 0.8657 & 0.8983 & 1.0000 & \\
\hline$D_{R} M_{3}$ & -0.3577 & 0.0398 & 0.1440 & 0.5887 & 0.7728 & 0.7949 & 0.8325 & 0.9880 & 1.0000 \\
\hline $\begin{array}{l}\text { Risk } \\
\text { premium } \\
\text { (CRRA=2) }\end{array}$ & -0.0856 & 0.7856 & 0.8507 & 0.7537 & 0.8266 & 0.8733 & 0.8351 & 0.6353 & 0.5649 \\
\hline
\end{tabular}

Notes: All correlations are significantly different from zero at $5 \%$ level or less except for those indicated by $\dagger$.

The first order LPM is very highly correlated with the second order LPM but its correlation with $D R M_{1}^{F G T}$, from which it differs only by standardisation on the threshold, falls to 0.67 . This reflects the scale dependence of the LPM measures and the household-specific nature of the threshold. The maximum value of $D R M_{1}^{L P M}$ is the threshold and so it will be higher for households with higher expected consumption.

The first order standardised LPM measure $\left(D R M_{1}^{F G T}\right)$ is quite highly correlated with $D R M_{1}(C R R A=1)$ but not so nearly highly correlated as is the second order measure $\left(D R M_{2}^{F G T}\right)$. This is because both $D R M_{1}$ and $D R M_{2}^{F G T}$ reflect risk aversion, while $D R M_{1}^{F G T}$ implies risk neutrality below the threshold. The weakness of $D R M_{2}^{F G T}$ is that it restricts preferences to be less sensitivity to risk located at low levels of consumption than would be the case in the absence of loss aversion. This becomes apparent when the risk aversion parameter is raised, with $D R M_{2}$ and $D R M_{3}$ being less closely correlated with $D R M_{2}^{F G T}$ than is $D R M_{1}$. The consumption levels of the households identified as most at risk by $D R M_{2}$ or $D R M_{3}$ are substantially lower, on average, than the consumption of those most at risk according to $D R M_{1}$. When aggregating across households, raising risk aversion implies placing greater weight on poorer households. The correlation between the downside risk measure and the risk premium with both computed for $\mathrm{CRRA}=2$ is only 0.63 . A risk measure reflecting the variability of medical expenditure across the full 
distribution does not identify the same households as most at-risk as does a measure focussed on the risk of falling below expectations. Because it is not defined with respect to expectations, the risk premium is higher for households with higher levels of consumption. Mean consumption among the top quartile of the Filipino sample households identified by the risk premium is more the two-thirds greater than mean consumption of the quartile most at risk according to $D R M_{2}$.

The correlation of each risk measure with the same measure computed at a different threshold is generally very high (around 0.9). ${ }^{23}$

\section{Which households face greatest risk?}

To explore systematic variation in exposure to medical expenditure risk we regress the log of a risk measure on household characteristics. For ease of presentation and to help in the identification of general patterns, the covariates included are aggregates of those used in the simulation of the consumption distributions. Rather than include each source of financing health care, we include an indicator of whether the household is in the bottom quartile of the distribution mean predicted medical expenditure under the counterfactual of no reliance on coping strategies as a ratio of the mean prediction with the financing actually deployed i.e. the ratio presented in the last row of Table 2. This ratio will be lower for households that deploy more coping strategies and so the indicator (bigh coping) identifies the households that exercise most informal and self insurance. We apply principal components analysis (PCA) to the battery of durables used to predict total and medical expenditure and identify households in the lowest quartile of the first factor score (low wealth). We also apply PCA to the indicators of poor housing conditions, water supply and sanitation and identify households above the median of the resulting index (poor housing).

Rather than enter each of the indicators of non-communicable diseases, we identify the presence of any such condition (chronic). We identify households in which there is no adult with more than a primary level education (low education). In addition, we include the log of (predicted) income, as well as all the remaining variables used to predict medical expenditure: log household size, household demographic composition, urban and region.

The regression estimates for the Philippines are presented in Table 4 for the CRRA $=1$ and CRRA $=2$ downside risk measures at the expected consumption threshold and for CRRA $=2$ at $80 \%$ of expected consumption. Using the first threshold, risk is increasing with income when the risk aversion parameter is 1 but there is no significant relationship at the higher value. This is further indication of the greater weight placed on low levels of consumption when the risk aversion parameter is increased. Even with the risk aversion parameter held at 2 , the positive correlation with income is restored when the threshold is reduced.

\footnotetext{
23 These correlations are not shown but are available on request.
} 
Table 4: (Semi) Elasticities of risk measures with respect to covariates - the Philippines

\begin{tabular}{|c|c|c|c|}
\hline & \multicolumn{2}{|c|}{ Threshold: E[consumption] } & \multirow{2}{*}{$\begin{array}{c}\text { Threshold: } 80 \% \\
\text { E[consumption] } \\
\ln \left(D R M_{2}\right)\end{array}$} \\
\hline & $\ln \left(D R M_{1}\right)$ & $\ln \left(D R M_{2}\right)$ & \\
\hline \multirow[t]{2}{*}{$\log$ (income) } & $0.519 * * *$ & 0.0753 & $0.527 * * *$ \\
\hline & $(0.0217)$ & $(0.0549)$ & $(0.0822)$ \\
\hline \multirow[t]{2}{*}{ high coping } & $-0.124 * * *$ & $-0.294 * * *$ & $-0.431 * * *$ \\
\hline & $(0.0131)$ & $(0.0334)$ & $(0.0568)$ \\
\hline \multirow[t]{2}{*}{ low wealth } & $0.207 * * *$ & $0.482 * * *$ & $0.733 * * *$ \\
\hline & $(0.0186)$ & $(0.0483)$ & $(0.0760)$ \\
\hline \multirow[t]{2}{*}{ chronic } & $0.278 * * *$ & $0.413^{* * *}$ & $0.649 * * *$ \\
\hline & $(0.0124)$ & $(0.0314)$ & $(0.0499)$ \\
\hline \multirow[t]{2}{*}{ low education } & $0.147 * * *$ & $0.380 * * *$ & $0.520 * * *$ \\
\hline & $(0.0162)$ & $(0.0417)$ & $(0.0675)$ \\
\hline \multirow[t]{2}{*}{ poor housing } & $0.137 * * *$ & $0.403^{* * *}$ & $0.553 * * *$ \\
\hline & $(0.0164)$ & $(0.0421)$ & $(0.0683)$ \\
\hline \multirow[t]{2}{*}{ urban } & $-0.272 * * *$ & $-0.686 * * *$ & $-1.127 * * *$ \\
\hline & $(0.0134)$ & $(0.0347)$ & $(0.0543)$ \\
\hline \multirow[t]{2}{*}{ ln hhold size } & $0.152 * * *$ & $0.367 * * *$ & $0.455 * * *$ \\
\hline & $(0.0192)$ & $(0.0489)$ & $(0.0745)$ \\
\hline$N$ & 9035 & 9035 & 9035 \\
\hline
\end{tabular}

Notes: Estimates are coefficients from OLS of log risk measure. Robust standard errors in parentheses. Descriptions of covariates are given in Appendix Table A1. All models also include household demographics and region dummies. ${ }^{*} \mathrm{p}<0.1,{ }^{* *} \mathrm{p}<0.05,{ }^{* * *} \mathrm{p}<0.01$

Households that rely most on coping strategies to pay for health care face the least exposure to medical expenditure risk irrespective of the preference parameter and threshold. This negative relationship is expected but, as will become apparent below, it is not an inevitable consequence of the simulation method. The magnitude of the difference is substantial. With the expected consumption threshold and $C R R A=1$, households that exercise coping strategies most are exposed to $12 \%$ lower downside risk. As the risk aversion parameter is raised, the difference rises to almost 30\%. This, as we have confirmed through examination of systematic variation in each component of the decomposition given by equation (13), is because coping strategies are most effective in reducing the variability of consumption below the threshold and the influence of this variability on the risk measure increases with risk aversion. The sensitivity of the risk measure to coping also increases as the threshold is reduced due to the fact that households resort to the sale of assets, borrowing, etc. most when medical expenses are extremely high.

Low wealth households with fewer assets are exposed to most risk. With CRRA $=1$, those in the lowest quartile of the wealth index face $21 \%$ more downside risk measured against expected consumption. This is consistent with health risks being more prevalent among the poor, while their formal health insurance coverage is lower in the Philippines. The least wealthy face almost 50\% higher risk when the risk aversion parameter is raised. This again reflects the greater weight placed in low levels of consumption when the risk aversion parameter is raised. Reducing the threshold, while holding risk aversion constant, also has a large impact on the sensitivity of the risk measure to wealth.

Presence of a chronic illness raises downside risk by a magnitude that is similar to the effect of low wealth. The relationship again strengthens as the risk aversion parameter is raised and the threshold is 
reduced. Making use of the decomposition, we have established that this is because chronic illness impacts most on the variability of consumption below the threshold. The least educated and those living in the worst conditions with respect to housing materials, water supply and sanitation face greatest exposure to risk. The first relationship results from the fact that education raises total expenditure by more than it does medical expenditure (Table 1), resulting in a rise in non-medical consumption with education. Urban households face almost 70\% lower risk than their rural counterparts with the threshold set at expected consumption and CRRA $=2$. Most likely this reflects higher health insurance coverage of the urban population. Larger households are exposed to more risk. A one percent increase in the size of the household is correlated with 0.37 percent more downside risk with the expected consumption threshold and CRRA $=2$.

Much, but certainly not all, of the systematic variation in risk exposure with household characteristics is consistent across countries. We examine this in Table 5 for the risk measure defined with respect to the $80 \%$ of income threshold and CRRA $=2$. This threshold is chosen since expected medical expenditures vary a great deal across countries. It may be considered inappropriate to compare risk relative to low expected out of pocket payments in Malaysia with risk relative to much higher expected payments in Bangladesh. It is clear that the Philippines, for no obvious reason, is an exception with respect to the relationship between risk and income. In all other countries, risk is lower at higher incomes. The elasticity is generally large in magnitude. In Laos, a 1 percent increase in income is associated with a 2.2 percent fall in the degree of risk exposure. Only in Malaysia is the magnitude of the elasticity substantially less than one.

Greater reliance on financing health care through sources other than income is associated with lower risk exposure in all countries but for China and Laos. It is noticeable from Table 2 that the effect of coping strategies on medical expenditures in the two latter countries is less than in all other countries other than Malaysia. Examining the estimates of the conditional mean functions reveals that savings are used to finance smaller (mean) health payments in Laos and this is true of other financing sources in China. The negative elasticities observed in Table 5 imply that such relationships hold at high quantiles of the distributions in these two countries.

Low wealth is correlated with greater exposure to risk in all countries but for Bangladesh and Laos. The lowest wealth quartile faces an increase of around 150\% in risk in Pakistan and China. The least wealthy actually face significantly lower risk in Laos. Presence of chronic conditions raises risk exposure in all countries. The effect is greatest in Laos, where it raises risk exposure by $90 \%$. Low education is positively correlated with increased risk in all countries but for Bangladesh and Malaysia. The lower risk faced by the least educated in Malaysia may be attributable to that country's tax financed public health system that is relatively effective in targeting the poor (O'Donnell, van Doorslaer et al. 2007) and apparently in affording protection from financial risk. However, we do find that households with low income and low wealth in Malaysia face higher risk. The relationship of risk with poor housing conditions displays the 
least consistency across countries. It is negative in Pakistan, China and Malaysia and positive in India and the Philippines. As in the Philippines, in Pakistan and Malaysia urban households are less exposed to risk than their rural counterparts but the opposite is true in Bangladesh and India.

Table 5: (Semi) Elasticities of risk measure with respect to covariates by country - threshold at $80 \%$ of income. Dependent variable: $\log$ of $\mathrm{DRM}_{2}$

\begin{tabular}{|c|c|c|c|c|c|c|c|}
\hline & Bangladesh & India & Pakistan & China & Laos & Malaysia & Philippines \\
\hline $\ln$ (income) & $\begin{array}{c}-1.064^{* * *} \\
(0.0952)\end{array}$ & $\begin{array}{c}-1.540 * * * \\
(0.0892)\end{array}$ & $\begin{array}{c}-0.849 * * * \\
(0.121)\end{array}$ & $\begin{array}{c}-1.298 * * * \\
(0.139)\end{array}$ & $\begin{array}{c}-2.215^{* * *} \\
(0.114)\end{array}$ & $\begin{array}{c}-0.450 * * \\
(0.184)\end{array}$ & $\begin{array}{c}0.446 * * * \\
(0.0730)\end{array}$ \\
\hline high coping & $\begin{array}{l}-0.0746 * \\
(0.0425)\end{array}$ & $\begin{array}{c}-0.345 * * * \\
(0.0468)\end{array}$ & $\begin{array}{c}-0.392 * * * \\
(0.0649)\end{array}$ & $\begin{array}{c}0.0786 \\
(0.0839)\end{array}$ & $\begin{array}{l}0.138 * * \\
(0.0594)\end{array}$ & $\begin{array}{l}-0.147 \\
(0.117)\end{array}$ & $\begin{array}{c}-0.398 * * * \\
(0.0491)\end{array}$ \\
\hline low wealth & $\begin{array}{c}0.0279 \\
(0.0483)\end{array}$ & $\begin{array}{c}0.100 * \\
(0.0578)\end{array}$ & $\begin{array}{l}1.497 * * * \\
(0.0858)\end{array}$ & $\begin{array}{c}1.584^{* * *} \\
(0.120)\end{array}$ & $\begin{array}{c}-0.219 * * * \\
(0.0672)\end{array}$ & $\begin{array}{c}0.411^{* *} \\
(0.170)\end{array}$ & $\begin{array}{c}0.662 * * * \\
(0.0678)\end{array}$ \\
\hline chronic & $\begin{array}{c}0.383 * * * \\
(0.0410)\end{array}$ & $\begin{array}{c}0.173 * * * \\
(0.0415)\end{array}$ & $\begin{array}{c}0.414 * * * \\
(0.0669)\end{array}$ & $\begin{array}{c}0.736 * * * \\
(0.0842)\end{array}$ & $\begin{array}{c}0.904 * * * \\
(0.0585)\end{array}$ & $\begin{array}{c}0.771 * * * \\
(0.111)\end{array}$ & $\begin{array}{c}0.606^{* * *} \\
(0.0439)\end{array}$ \\
\hline low education & $\begin{array}{c}-1.064 * * * \\
(0.0661)\end{array}$ & $\begin{array}{c}0.394^{* * *} \\
(0.0486)\end{array}$ & $\begin{array}{c}0.452 * * * \\
(0.0794)\end{array}$ & $\begin{array}{c}0.490 * * * \\
(0.0978)\end{array}$ & $\begin{array}{c}0.232 * * * \\
(0.0676)\end{array}$ & $\begin{array}{c}-0.563 * * * \\
(0.157)\end{array}$ & $\begin{array}{c}0.499 * * * \\
(0.0593)\end{array}$ \\
\hline poor housing & $\begin{array}{c}0.0382 \\
(0.0430)\end{array}$ & $\begin{array}{c}0.281 * * * \\
(0.0615)\end{array}$ & $\begin{array}{c}-0.275 * * * \\
(0.0868)\end{array}$ & $\begin{array}{c}-0.648 * * * \\
(0.126)\end{array}$ & $\begin{array}{l}-0.0925 \\
(0.0589)\end{array}$ & $\begin{array}{c}-0.827 * * * \\
(0.158)\end{array}$ & $\begin{array}{c}0.503 * * * \\
(0.0599)\end{array}$ \\
\hline urban & $\begin{array}{c}0.482 * * * \\
(0.0487)\end{array}$ & $\begin{array}{l}0.128 * * \\
(0.0552)\end{array}$ & $\begin{array}{c}-0.977 * * * \\
(0.0778)\end{array}$ & & $\begin{array}{l}-0.0927 \\
(0.0858)\end{array}$ & $\begin{array}{c}-1.162 * * * \\
(0.134)\end{array}$ & $\begin{array}{c}-1.008 * * * \\
(0.0482)\end{array}$ \\
\hline In hhold size & $\begin{array}{c}-0.468 * * * \\
(0.0701)\end{array}$ & $\begin{array}{c}-0.260 * * * \\
(0.0711)\end{array}$ & $\begin{array}{c}0.661 * * * \\
(0.0973)\end{array}$ & $\begin{array}{c}0.567 * * * \\
(0.142)\end{array}$ & $\begin{array}{c}0.879 * * * \\
(0.0937)\end{array}$ & $\begin{array}{c}0.544^{* * *} \\
(0.176)\end{array}$ & $\begin{array}{c}0.454 * * * \\
(0.0664)\end{array}$ \\
\hline insurance & & & & $\begin{array}{c}-0.894 * * * \\
(0.158)\end{array}$ & & $\begin{array}{c}-0.825 * * * \\
(0.157)\end{array}$ & \\
\hline$N$ & 5025 & 6645 & 3888 & 3711 & 4254 & 5137 & 9035 \\
\hline
\end{tabular}

Notes: Estimates are coefficients from OLS of $\log \mathrm{DRM}_{2}$. Robust standard errors in parentheses. Descriptions of covariates are given in Appendix Table A1. All models also include household demographics, region dummies and (for some countries) ethnicity. Urban is excluded for China since there is no urban/rural variation within each region. ${ }^{*} \mathrm{p}<0.1,{ }^{* *} \mathrm{p}<0.05,{ }^{* * *} \mathrm{p}<0.01$

The WHS asks about the health insurance coverage of each household member. In order to avoid obvious endogeneity, we restrict attention to coverage that is reported to be mandatory. Two countries have sufficient prevalence of mandatory health insurance to make estimation feasible - China and Malaysia. ${ }^{24}$ While we cannot guarantee that this information is truly exogenous to medical expenditures, we do use it in the simulation exercise and report here how risk exposure varies with coverage. The variable entered is the proportion of household members with mandatory coverage. The coefficient is strongly significant and negative in both countries. The estimates indicate that in a household in which all members are covered, risk exposure is $83-89 \%$ lower than in households in which no one is covered. If there is endogeneity arising from adverse selection, then these will be underestimates of the risk protection afforded. Of course, there could be other differences between households with and without coverage that are not controlled for in the regression and influence the estimate. Nevertheless, we note that, at the very least, the finding is consistent with a substantial financial protection effect from health insurance.

24 There is also a sufficient number reporting this type of coverage in the Philippines but we do not use the information. The Philippines has had a National Health Insurance Program since 1995. Participation is not mandatory, however. In 2002, the majority of those enrolled had volunteered to enter the scheme and paid a premium. Analysis revealed that those declaring coverage had higher medical expenditures, suggesting adverse selection and resulting endogeneity concerns. 
We have established that the negative relationship between risk and insurance is driven mainly by a lower loss arising from the variability of consumption below the threshold (equivalently, the uncertainty of medical expenses above a respective threshold). In China, a household in which all members have health insurance coverage faces a $152 \%$ lower loss from uncertainty about medical expenses in excess of $20 \%$ of income than does a household in which no one is covered. In Malaysia, the respective figure is $217 \%$. If we dare to interpret these as causal effects, then they indicate that the gain from insurance is obtained, as conventional theory maintains, through the reduction of uncertainty.

\section{Decomposition of downside risk}

The decomposition given by equation (13) of the CRRA downside risk measure calculated at all three risk aversion parameters and all three thresholds is given in Table 6 for the Philippines. Each risk measure and its constituent parts are averaged across households. The first column gives the (mean) probability of consumption falling below the threshold. The average probability that consumption will fall below its expected value is 0.27 . With CRRA $=1$, the larger part of the expected loss if consumption does fall short of the mean is due to the predictably low level of consumption $\left(L_{p}=0.19\right)$. The loss due to the variability of consumption below the threshold $\left(L_{\nu}=0.12\right)$ is roughly two-thirds as large. As the threshold is reduced, the probability of falling below the threshold obviously falls and reaches 0.06 , on average, at $80 \%$ of the expectation. Reducing the threshold has the opposite impact on the expected loss below the threshold. The loss is less likely but its magnitude should it occur is greater. Both components of the expected loss rise in magnitude by roughly equal proportions such that their relative size remains approximately constant.

Raising the risk aversion parameter has a dramatic impact on the decomposition. The loss due to the variability of consumption below the threshold becomes larger than that due the predictably low level of consumption if the threshold is not reached. This is to be expected. With greater risk aversion the welfare loss from uncertainty is increased. As the threshold is reduced, $L_{p}$ rises relatively more than $L_{\nu}$ but it never becomes absolutely greater than $L_{v}$. At CRRA $=3$, the risk measure becomes relatively insensitive to the threshold since the decreasing probability of the threshold not being realised is fully offset by the increasing expected loss. This confirms our assertion that catastrophic risks can be captured even with a relatively high threshold provided that risk aversion is set sufficiently high such that a great deal of weight is placed on prospects that leave consumption far short of the threshold.

Table 6: Decomposition of downside risk measures by degree of risk aversion and threshold: means of each component - the Philippines

\begin{tabular}{|c|c|c|c|c|c|c|c|c|c|c|}
\hline \multirow[b]{2}{*}{ Threshold $(\xi)$} & \multirow[b]{2}{*}{$F_{c}(\xi)$} & \multicolumn{3}{|c|}{$\mathrm{CRRA}=1$} & \multicolumn{3}{|c|}{$\mathrm{CRRA}=2$} & \multicolumn{3}{|c|}{$\mathrm{CRRA}=3$} \\
\hline & & $\mathrm{DRM}_{1}$ & $\mathrm{~L}_{\mathrm{p}}$ & $\mathrm{L}_{\mathrm{v}}$ & $\mathrm{DRM}_{2}$ & $\mathrm{~L}_{\mathrm{p}}$ & $\mathrm{L}_{\mathrm{v}}$ & $\mathrm{DRM}_{3}$ & $\mathrm{~L}_{\mathrm{p}}$ & $\mathrm{L}_{\mathrm{v}}$ \\
\hline $\mathrm{E}$ [consumption] & 0.2673 & 0.07814 & 0.1901 & 0.1235 & 0.6414 & 0.2168 & 2.5870 & 0.3461 & 0.003442 & 1.5922 \\
\hline $80 \%$ income & 0.08955 & 0.05747 & 0.3444 & 0.2299 & 0.6198 & 0.8631 & 5.9514 & 0.3458 & 0.2411 & 3.9510 \\
\hline $80 \%$ E[consumption] & 0.06389 & 0.05030 & 0.4159 & 0.2737 & 0.6125 & 1.3113 & 7.6094 & 0.3457 & 0.4453 & 5.0213 \\
\hline
\end{tabular}

Notes: Terms correspond to the components of the decomposition given by equation (13) averaged over households. $\mathrm{DRM}_{2}$ and its components multiplied by $10000 . \mathrm{DRM}_{3}$ and its components multiplied by 1000000 . 
The decomposition of $\mathrm{DRM}_{2}$ is presented in Table 7 for each country. The threshold is $80 \%$ of income. The values of $D R M_{2}$ itself should not be compared across countries since they are scale dependent. The (mean) probability that non-medical consumption falls below $80 \%$ of income (equivalently, medical expenditure exceeds $20 \%$ of income) is highest in Laos and Pakistan and lowest in Malaysia and the Philippines. In all countries, the expected loss if consumption does fall below the threshold is dominated by the loss due to the variability of consumption, which accounts for over $80 \%$ of the loss in all countries but for Malaysia. The lower contribution from the variability of consumption (medical expenditure) in Malaysia presumably reflects the more extensive public health care provision in that country that protects against extremely high medical expenses. The relative contribution from the variability of expenses is highest $(>90 \%)$ in India, China and Laos. In these countries, not only is there a very high probability that medical expenditures exceed $20 \%$ of income but there is a great deal of variability above this threshold implying a risk of facing catastrophically high expenses. This reflects the lack of health insurance coverage (in 2002) and heavy reliance on OOP financing in these countries.

Table 7: Decomposition of downside risk measures by country: means of each component CRRA $=2$, threshold is $80 \%$ of income $(\xi)$

\begin{tabular}{lccccc}
\hline & $D R M_{2}$ & $F_{c}(\xi)$ & $L_{p}$ & $L_{v}$ & $L_{v}\left(L_{p}+L_{v}\right)$ \\
\hline Bangladesh & 0.2805 & 0.1324 & 0.2789 & 1.5666 & 0.8489 \\
India & 1.5210 & 0.1492 & 0.6431 & 9.0736 & 0.9338 \\
Pakistan & 1.0515 & 0.1648 & 0.6489 & 5.2476 & 0.8900 \\
China & 5.7497 & 0.1230 & 3.0343 & 36.053 & 0.9224 \\
Laos & 34.993 & 0.1699 & 11.560 & 173.09 & 0.9374 \\
Malaysia & 0.6061 & 0.03352 & 4.0994 & 10.184 & 0.7130 \\
Philippines & 0.6198 & 0.08955 & 0.8631 & 5.9514 & 0.8733 \\
\hline
\end{tabular}

Notes: Terms correspond to the components of the decomposition given by equation (13) averaged over households. $D R M_{2}, L_{p}$ and $L_{v}$ multiplied by 10000 .

In which country is medical expenditure risk highest?

Our primary goal is to measure medical expenditure risk at the household level with the aim of identifying those households that are most exposed to risk and would benefit most from policy interventions that provide subsidised health care or extend health insurance coverage. A further use of the measures is to assess the protection against medical expenditure risk provided within a country and to compare it with that offered in neighbouring countries or in others at similar levels of development. For comparative purposes it is necessary to use a measure that is independent of the scale of the monetary units in which risk is measured. For this reason, we employ the normalised CRRA $=1$ measure, $D R M_{1}^{N}$. As with the comparisons made in Table 5 , we focus on the $80 \%$ of income threshold.

Inspection of the cumulative empirical distributions of the risk measure presented in Figure 1 suggests that households' exposure to risk is unambiguously greatest in Laos and least in Malaysia. We check whether this is indeed the case by testing for stochastic dominance using Bennett's two-stage approach (Bennett 2011). This has the important advantage over alternative tests, e.g. (McFadden 1989; Barrett and Donald 2003), of allowing the four mutually exclusive states of nature - equality of distributions, strong 
stochastic dominance in each direction and crossing of the distributions - to be distinguished with a high, known probability. In the first stage, the null of equality is tested against the alternative of inequality using a two-sided Kolmogorov-Smirnov (KS) test. If this null is rejected, then testing proceeds to a second stage in which the minimum of the one-sided KS test statistics is used to distinguish between the three remaining possible states of nature. The sequential nature of the test procedure is taken into account in the derivation of critical values consistent with predefined probabilities of Type I errors at each stage. ${ }^{25}$ We adopt a $1 \%$ level of significance at the first stage and a $10 \%$ level at the second stage. This is conservative with respect to concluding that there is strong stochastic dominance since a lower first-stage level of significance reduces the probability of falsely rejecting the null of equality and a higher secondstage significance level corresponds to a greater probability of falsely rejecting dominance in favour of the hypothesis of crossing distributions. When the test indicates crossing of distributions at these significance levels, we reduce the second-stage level (to $5 \%$ and $1 \%$ ) to check whether the conclusion switches to dominance.

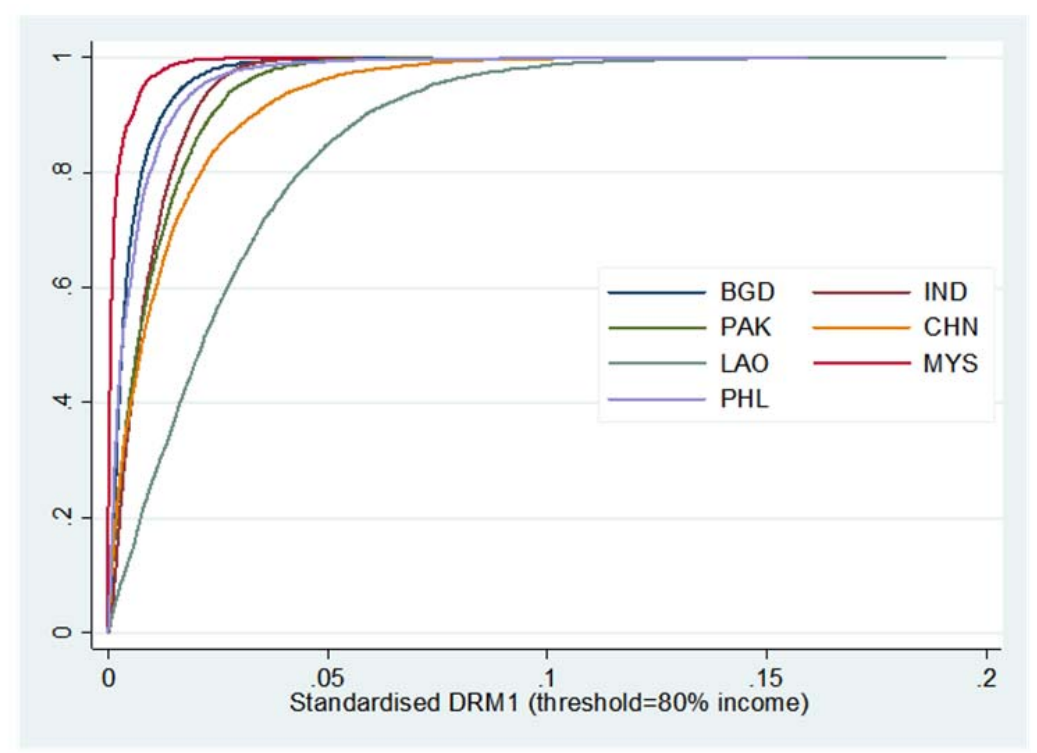

\section{Figure 1: Cumulative distribution of standardized downside risk measure, with CRRA=1 and threshold at $80 \%$ of income by country}

The tests confirm that medical expenditure risk is unambiguously highest in Laos and lowest in Malaysia (Table 8). The risk distribution in Laos dominates (i.e. lies below) that of all other countries and that in Malaysia is dominated by all others. Irrespective of where a household is located in the distribution, its risk exposure would be lower if it were in Malaysia and it would be greater were it in Laos. The extreme positions of these two countries are consistent with their respective provisions of subsidised public health care and health insurance. Malaysia is recognised as a leading example, not only in Asia, of ensuring that subsidised public health care does reach the poor and of protecting the population from medical expenses. In Laos, public health care provision and insurance coverage are sparse, even by the standards of a low income country.

25 We adopt the critical values derived by Bennett (2011) for his asymptotic test, which are asymptotically valid provided the distributions are continuous. Bennett also proposes a resampling procedure. 
Table 8: Tests for stochastic dominance of risk distributions across countries Normalised CRRA $=1$ risk measure $\left(D R M_{1}^{N}\right)$ with threshold at $80 \%$ of income

\begin{tabular}{|c|c|c|c|c|c|c|}
\hline & Bangladesh & India & Pakistan & China & Philippines & Malaysia \\
\hline Laos & $\succ$ & $\succ$ & $\succ$ & $\succ$ & $\succ$ & $\succ$ \\
\hline Bangladesh & & $\prec$ & $\mathrm{x}$ & $\mathrm{x}$ & $\mathrm{x}$ & $\succ$ \\
\hline India & & & $\mathrm{x}$ & $\mathrm{x}$ & $\succ^{*}$ & $\succ$ \\
\hline Pakistan & & & & $\mathrm{x}$ & $\mathrm{x}$ & $\succ$ \\
\hline China & & & & & $\succ$ & $\succ$ \\
\hline Philippines & & & & & & $\succ$ \\
\hline
\end{tabular}

Notes: Bennett (2011) asymptotic bidirectional test for stochastic dominance. $\succ(\prec)$ indicates that the row (column) distribution first order stochastically dominates the column (row) distribution. $\mathrm{x}$ indicates that the distributions cross. Significance level is $1 \%$ for first stage test of null of equality of distributions. Significance level for second stage test (to distinguish dominance from crossing of distributions) is $10 \%$ except where indicated by $*$. In this one case, the test indicates crossing at significance levels of $10 \%$ and $5 \%$ but indicates dominance in the direction indicated at $1 \%$.

The risk distribution in China crosses that of each of the three countries of the Indian subcontinent but dominates that of the Philippines. Inspection of the Figure 1 reveals that the ambiguity of China's position relative to South Asia is attributable to the bottom half on the distributions. From the median upward, medical expenditure risk is higher in China than it is in all other countries except for Laos. China has the second highest mean medical expenditure risk (Table 9). It is interesting, and presumably not a coincidence, that China and Laos are the two countries in which risk is not substantially and significantly lower for households that rely most on informal and self insurance mechanisms to pay for health care (Table 6). This suggests, but does not confirm, that saving, borrowing etc. are less effective in these countries in protecting consumption when medical expenses must be paid. In interpreting the results for China it is important to keep two features of the data in mind. First, the Chinese sample is not nationally representative and consists of less than 4000 households. Second, the data are from 2002. Since then, besides very rapid economic growth, there has been a substantial increase in insurance coverage, particularly of the rural population. Our estimates lead us to expect this to have resulted in a marked decrease in risk exposure. The estimates presented in Table 5 showed that risk decreases substantially with income, wealth and insurance coverage in China. It would be interesting to measure medical expenditure risk in China using a larger, more representative recent sample.

Medical expenditure risk is unambiguously lower in the Philippines that it is in China and India. The latter result is obtained only when the significance level at the second stage of the stochastic dominance test is reduced to $1 \%$. Otherwise, the risk distribution in the Philippines crosses that in India, as well as the distributions for both Bangladesh and Pakistan. Despite there being a National Health Insurance Program (NHIP) in operation since 1995 in the Philippines, risk exposure has not been reduced below levels found in the Indian subcontinent, where there is no such program. In 2002-03, when the WHS data were collected, the NHIP was officially claimed to cover around 65\% of the Philippines' population but coverage was extremely shallow with only $9 \%$ of total spending on health care being financed from the 
program leaving high levels of risk exposure (Obermann, Jowett et al. 2006). ${ }^{26}$ Medical expenditure risk is lower in Bangladesh than it is in India. Otherwise, no unambiguous conclusions can be reached in comparing the three South Asian countries.

In addition to mean risk exposure, Table 9 also contains measures of the OOP budget shares actually incurred by households. As observed earlier, these shares estimated from these World Health Survey data are rather high reflecting the concentration of the survey on health and health spending. This is not so important for the present purpose, which is to compare countries on the basis of both our ex ante risk measure and expost realised health payments. The measures that have been adopted hitherto to assess and compare financial protection from medical expenditures across countries have been derived from the realised budget shares. One popular measure is the proportion of households for whom health spending exceeds some fraction (here 20\%) of the budget. Ordering countries by either this catastrophic payment headcount or the mean budget share results in quite a different ranking from that based on the risk measure. Malaysia remains at the bottom but the top of the table changes dramatically. The three countries of the Indian subcontinent have the highest expost budget shares and catastrophic payments, while Laos and China move down to the middle of the table by these measures. If one is seeking to measure risk exposure then mean expenditure is obviously not an appropriate statistic. The expost catastrophic payment headcount attempts to identify extremities of the distribution but it does so by focusing exclusively on the probability of being above a single point. The ex ante risk measure is a function of the distribution beyond the threshold, including its variance, and it weights deviations from the threshold differentially in accordance with the value of the risk aversion parameter. The South Asian countries have relatively lower measured exposure to medical expenditure risk despite high spending on health care because that spending is more predictable.

Table 9: Medical expenditure risk and realised medical expenditure budget shares by country Normalised CRRA $=1$ risk measure with threshold at $80 \%$ of income

\begin{tabular}{|c|c|c|c|c|}
\hline & \multicolumn{2}{|c|}{$D R M_{1}^{N}$} & \multicolumn{2}{|c|}{$\begin{array}{c}\text { Realised medical } \\
\text { expenditure budget share } \\
(\mathrm{w})\end{array}$} \\
\hline & Mean & $\begin{array}{l}\text { Standard } \\
\text { deviation }\end{array}$ & $\begin{array}{l}\text { Mean } \\
(\%)\end{array}$ & $\begin{array}{l}\text { Proportion } \\
\text { with } w>20\end{array}$ \\
\hline Laos & 0.02725 & 0.02355 & 12.813 & 0.2179 \\
\hline China & 0.01297 & 0.01552 & 9.3766 & 0.1612 \\
\hline Pakistan & 0.009887 & 0.009993 & 13.371 & 0.2317 \\
\hline India & 0.008895 & 0.007480 & 13.042 & 0.2263 \\
\hline Philippines & 0.006166 & 0.008776 & 8.4150 & 0.1346 \\
\hline Bangladesh & 0.005198 & 0.006175 & 13.403 & 0.2247 \\
\hline Malaysia & 0.001699 & 0.003294 & 3.5954 & 0.04031 \\
\hline
\end{tabular}

Notes: Countries are ordered by the mean of $D R M_{1}^{N}$. Realised medical expenditure budget share is actual spending on health care as a proportion of total household spending.

${ }^{26}$ Household survey data indicate that a much lower percentage of the population are aware of having NHIP coverage (Capuno et al, 2009). 


\section{CONCLUSION}

Health insurance coverage is woefully lacking in most low and middle income countries leaving households exposed to substantial risk from medical expenses. Measurement of this risk can be used to a) assess the case for health financing reforms, b) design reforms, c) identify households to be targeted by reforms, d) evaluate the impact of reforms. We have proposed measures of downside risk arising from uninsured medical expenditures. Unlike the risk premium, these measures focus on exposure to the risk of unusually high expenses. Coverage of these risks is arguably the priority in countries with resources insufficient to provide comprehensive coverage. Unlike ex post measures of catastrophic payments based on medical expenditures actually incurred, the measures capture exposure to risk and permit its comparison across households. The measures can be derived from a model of reference-dependent utility with loss aversion in which the threshold that defines a loss is part of preferences. A class of measures can be decomposed into the probability that medical expenditure exceeds a threshold, the loss due to the predictably low level of consumption should it do so and the further loss arising from the variability of consumption at low levels.

Application to comparable cross-country data from Asia illustrates the added value of the approach relative to existing measures. The downside risk measures are not highly correlated across households with the risk premium. The countries in which exposure to downside medical expenditure risk is estimated to be highest are not the same as those in which mean spending on medicine as a proportion of income is highest. In general, households that are most disadvantaged with respect to income, wealth and education, as well as those in which there is chronic illness, are exposed to the greatest medical expenditure risk. Risk is also higher for those households without formal health insurance coverage and that have less resort to informal and self insurance. At plausible levels of risk aversion, the variability in consumption at low levels induced by medical expenses is the larger component of the welfare loss.

The approach could be further developed in a number of dimensions. As with all the literature on reference-dependent utility, definition of the threshold with respect to which downside risk is assessed is a particularly thorny problem. While we favour expected consumption because household preferences can be plausibly defined with respect to this reference, it is recognised that this may not sufficiently capture catastrophic risks. In addition, it may impede comparison across households and countries facing different expectations. The first reservation can be ameliorated by setting the risk aversion parameter sufficiently high such that draws of particularly high medical expenses (low consumption) are weighted heavily. The second reservation is somewhat misplaced providing the objective is to measure risk. The risk measure can be complemented by an indicator of the average burden of medical expenditures. Nonetheless, the risk that medical expenses absorb a large proportion of income appears to attract widespread concern. An income-related threshold will be preferred by many. The difficulty is then the arbitrariness of the chosen proportion. Choice of an appropriate threshold would benefit from surveys 
seeking to elicit the nature of the risks individuals fear in relation to medical expenses. Are there benchmarks against which losses are defined? Are risks perceived in relation to expectations or incomes?

It is perhaps worth clarifying that our assumption that income is fixed and risk only arises through medical expenditures is not a limitation. Of course, uncertain illness threatens consumption through both earnings losses and spending on health care. A measure of welfare loss from health risk should capture both. But this is not our objective. Protection against earnings losses and protection against medical expenditures are provided through two separate policy instruments - sickness/disability insurance and health insurance. Design of each requires evidence on the respective risk. We are concerned with medical expenditure risk with a view to the design of health insurance. Health shocks will generate co-movements of income and health expenditure. Measuring the risk from the latter requires some means of controlling for the former. We have done this by predicting expected income given observables that intentionally do not include indicators of health shocks.

There is no doubt that estimation of the distribution of medical expenditures faced by a household would be better achieved from longitudinal data that make it possible to uncover the time series properties of this variable (Feenberg and Skinner 1994; French and Jones 2004). It would be informative to estimate the risk measures we propose with such data. This could be attempted in a high income country, such as the US, where there are substantial OOP payments for health care. In the developing world there are very few panels of sufficient length available to make this feasible. Rather than aim for the best possible estimation using a rare dataset, we prefer to demonstrate what is achievable with the cross-section data more commonly available. This comes at the price of imposing some strong assumptions regarding the nature of the variation in medical expenditures and it demands caution in the interpretation of results which may reflect correlations rather than effects. The cross-section data we have used from the World Health Survey, while being attractive for cross-country comparisons, are limited in the degree of detail on non-health expenditures and, in some cases, sample size. From the perspective of a particular country, it would be worthwhile to estimate risk exposure using data that more accurately measure medical relative to other expenditures. Notwithstanding these limitations, the current application has generated plausible and interesting findings, which suggests that there is promise in the approach.

We measure exposure to the risk of medical expenditures that remains after the exercise of self and informal insurance. The measure reflects the fact that a household confronted with a medical bill of $\$ 1000$ that has savings or credit to draw on is in a better position that another household facing the same bill without these options. However, informal insurance mechanisms are imperfect substitutes for formal insurance. The household that uses up its savings, sells its assets or falls into debt today to pay for health care is exposed to more risk in the future and through the loss of productive assets may enter a downward spiral into poverty. Further, possession of self-insurance options may be a response to inflated aversion to risk. Then, the consumption variation remaining after the exercise of these options is not that which is relevant to measurement of the welfare loss from risk (Chetty and Looney 2006). These are 
legitimate reservations about the measures proposed here. Dealing with them would require moving to a dynamic model.

Part of the risk from facing uninsured medical expenses is that illness will strike and consumption will need to be sacrificed to pay for health care. Another important part of the risk in low income settings is that even essential health care cannot be afforded when illness does occur. Our measure does not capture this second risk. We simulate the distribution of medical expenditure faced by a household conditional on its ability to pay. This is intentional in order to respect a budget constraint. If poor households forgo health care when it is needed, then they will be predicted to face lower health expenditures and our measure does not capture catastrophes resulting from forgone essential treatment. This is as it should be since we are aiming to measure financial risk. The risk of not being able to afford essential health care is in the domain of health. Incorporating this would require extending the analysis to allow welfare to depend on health as well as consumption. 


\section{REFERENCES}

Abdellaoui, M. (2000). "Parameter-free elicitation of utility and probability weighting functions." Management Science 46(11): 1497-1512.

Abdellaoui, M., H. Bleichrodt, et al. (2007). "Loss Aversion Under Prospect Theory: A Parameter-Free Measurement." Management Science 53(10): 1659-1674.

Arokiasamy, P., M. Guruswamy, et al. (2006). Health System Performance Assessment: World Health Survey, 2003 - India. Mumbai, Geneva, New Delhi, International Institute for Population Sciences and World Health Organization.

Arrow, K. J. (1971). Essays in the Theory of Risk Bearing. Amsterdam, North Holland.

Asfaw, A. and J.B. von Braun (2004). "Is Consumption Insured against Illness? Evidence on Vulnerability of Households to Health Shocks in Rural Ethiopia." Economic Development and Cultural Change 53(1): 115-129.

Barrett, G. F. and S. G. Donald (2003). "Consistent tests for stochstic dominance." Econometrica 71(1): 71-104.

Bell, D. E. (1985). "Disappointment in Decision Making under Uncertainty." Operations Research 33(1): $1-27$.

Bennett, C. J. (2011). On bidirectional tests for stochastic dominance. Department of Economics, Vanderbilt University. Nashville.

Blomqvist, E. (1997). "Optimal non-linear health insurance." Journal of Health Economics 16(3): 303321.

Breitmeyer, C., H. Hakenes, et al. (2004). "From poverty measurement to the measurement of downside risk." Mathematical Social Sciences 47: 327-348.

Capuno, J. J., S. A. Quimbo, et al. (2009). "Household out-of-pocket health spending, health insurance coverage, and children's school attendance in the Philippines." Philippine Review of Economics 46(2): 155-182.

Chakravarty, S. R., J. Deutsch, et al. (2008). "On the Watts multidimensional poverty indicator and its decomposition." World Development 36(6): 1067-1077.

Chetty, R. and A. Looney (2006). "Consumption smoothing and the welfare consequences of social insurance in developing countries." Journal of Public Economics 90: 2351-2356.

Chua, H. T. and J. Cheah (2012) "Financing Universal Coverage in Malaysia: a case study." BMC Public Health 12(Suppl 1): S1-S7.

Cook, B. L. and W. G. Manning (2009). "Measuring Racial/Ethnic Disparities across the Distribution of Health Care Expenditures." Health Services Research 44(5p1): 1603-1621.

Dercon, S. and P. Krishnan (2000). "In Sickness and in Health: Risk Sharing within Households in Rural Ethiopia." Journal of Political Economy 108(4): 688-727.

Duan, N., W. G. Manning, et al. (1983). "A comparison of alternative models of the demand for health care." Journal of Business and Economic Statistics 1: 115-126.

Engelhardt, G. V. and J. Gruber (2011). "Medicare Part D and the financial protection of the elderly." American Economic Journal: Economic Policy 3(4): 77-102.

Feenberg, D. and J. Skinner (1994). "The risk and duration of catastrophic health care expenditures." The Review of Economics and Statistics 76(4): 633-647.

Feldstein, M. (1971). "A new approach to national health insurance." Public Interest 23: 93-105.

Feldstein, M. and J. Gruber (1995). A Major Risk Approach to Health Insurance Reform. Tax Policy and the Economy, Volume 9. J. M. Poterba. Cambridge, MA, MIT Press.

Fennema, H. and M. V. Assen (1998). "Measuring the utility of losses by means of the tradeoff method." Journal of Risk and Uncertainty 17(3): 277-96.

Finkelstein, A. and R. McKnight (2008). "What did Medicare do? The initial impact of Medicare on mortality and out of pocket medical spending." Journal of Public Economics 92: 1644-1668.

Fishburn, P. C. (1977). "Mean-Risk Analysis with Risk Associated with Below-Target Returns." The American Economic Review 67(2): 116-126.

Foster, J., J. Greer, et al. (1984). "A Class of Decomposable Poverty Measures." Econometrica 52: 761 766.

French, E. and J. B. Jones (2004). "On the Distribution and Dynamics of Health Care Costs." Journal of Applied Econometrics 19(6): 705-721. 
Genoni, (2012) M. E. "Health Shocks and Consumption Smoothing: Evidence from Indonesia." Economic Development and Cultural Change 60(3): 475-506.

Gertler, P. and J. Gruber (2002). "Insuring consumption against illness." American Economic Review 92(1): 51-70.

Gheyssens, J. and I. Günther (2012). Risk experiments in gains and losses: A case study for Benin. UNUWIDER Working Paper No. 2012/38 Helsinki.

Gruber, J. (2006). The role of consumer payments for health care: Lessons from the RAND Health Insurance Experiment and Beyond. The Henry J. Kaiser Family Foundation. Cambridge MA.

Hagenaars, A. (1987). "A Class of Poverty Indices." International Economic Review 28(3): 583-607.

Islam, A. and P. Maitra (2012) "Health shocks and consumption smoothing in rural households: Does microcredit have a role to play?" Journal of Development Economics 97(2): 232-243.

Jarrow, R. and F. Zhao (2006). "Downside Loss Aversion and Portfolio Management." Management Science 52(4): 558-566.

Kahneman, D. and A. Tversky (1979). "Prospect Theory: An Analysis of Decision under Risk." Econometrica 47: 263-291.

Kale, J. K. (2006). "Growth Optimization with Downside Protection: A New Paradigm for Portfolio Selection." The Journal of Behavioral Finance, 7(1): 146-150.

Kimball, M. S. (1990). "Precautionary Saving in the Small and in the Large." Econometrica 58(1): 53-73.

Köbberling, V. and P. P. Wakker (2005). "An Index of Loss Aversion." Journal of Economic Theory 122: 119-131.

Kőszegi, B. and M. Rabin (2006). "A Model of Reference-Dependent Preferences." The Quarterly Journal of Economics 121(4): 1133-1165.

Loomes, G. and R. Sugden (1986). "Disappointment and Dynamic Consistency in Choice under Uncertainty." Review of Economic Studies 53(2): 271-282.

McFadden, D. (1989). Testing for stochastic dominance. Studies in the Economics of Uncertainty. In Honour of Josef Hadar. T. B. Fomby and T. K. Seo. New York, Springer Verlag: 113-134.

Menezes, C., C. Geiss, et al. (1980). "Increasing Downside Risk." American Economic Review 70(5): 921 932.

Meyer, D. and J. Meyer (2005). "Relative risk aversion: What do we know?" Journal of Risk and Uncertainty 31(3): 243-262.

Mohanan, M. (forthcoming) "Causal Effects of Health Shocks on Consumption and Debt: QuasiExperimental Evidence from Bus Accident Injuries." Review of Economics and Statistics.

Moussavi, S., S. Chatterji, et al. (2007). "Depression, chronic diseases, and decrements in health: Results from the world health surveys." The Lancet 370: 851-858.

Newhouse, J., P. (1993). Free for All? Lessons from the RAND Health Insurance Experiment. Cambridge, MA, Harvard University Press.

Nyman, J. A. (1999). "The value of health insurance: the access motive." Journal Health Economics 18(2): $141-52$

O'Donnell, O., E. van Doorslaer, et al. (2007). "The incidence of public spending on health care: comparative evidence from Asia." World Bank Economic Review 21(1): 93-123.

Obermann, K., M. R. Jowett, et al. (2006). "Social health insurance in a developing country: The case of the Philippines." Social Science \&amp; Medicine 62(12): 3177-3185.

Pauly, M. V., F. E. Blavin, et al. (2009). "How private, voluntary health insurance can work in developing countries." Health Affairs 28(6): 1778-87.

Roy, A. D. (1952). "Safety First and the Holding of Assets." Econometrica 20(3): 431-449.

Sugden, R. (2003). "Reference-Dependent Subjective Expected Utility." Journal of Economic Theory 111: 172-191.

Tovar, P. (2009). "The effects of loss aversion on trade policy: Theory and evidence." Journal of International Economics 78(1): 154-167.

Townsend, R. M. (1994). "Risk and Insurance in Village India." Econometrica 62(3): 539-91.

Wagstaff, A. and E. Van Doorslaer (2003). "Catastrophe and impoverishment in paying for health care: with applications to Vietnam 1993-98." Health Economics 12: 921-934.

Watts, H. (1968). An economic definition of poverty. On understanding poverty. D. P. Moynihan. New York, Basic Books.

World Health Organization (2000). World Health Report 2000. Health systems: improving performance. Geneva, World Health Organization. 
World Health Organization (2010). The World Health Report 2010. Health systems financing: the path to universal coverage. Geneva, World Health Organization.

World Health Organization. (2011). "World Health Survey."http://www.who.int/healthinfo/survey/en/. Xu, K., D. E. Evans, et al. (2003). "Household catastrophic health expenditure: a multicountry analysis." Lancet 362: 111-17. 


\section{Appendix}

Table A1: Description of variables

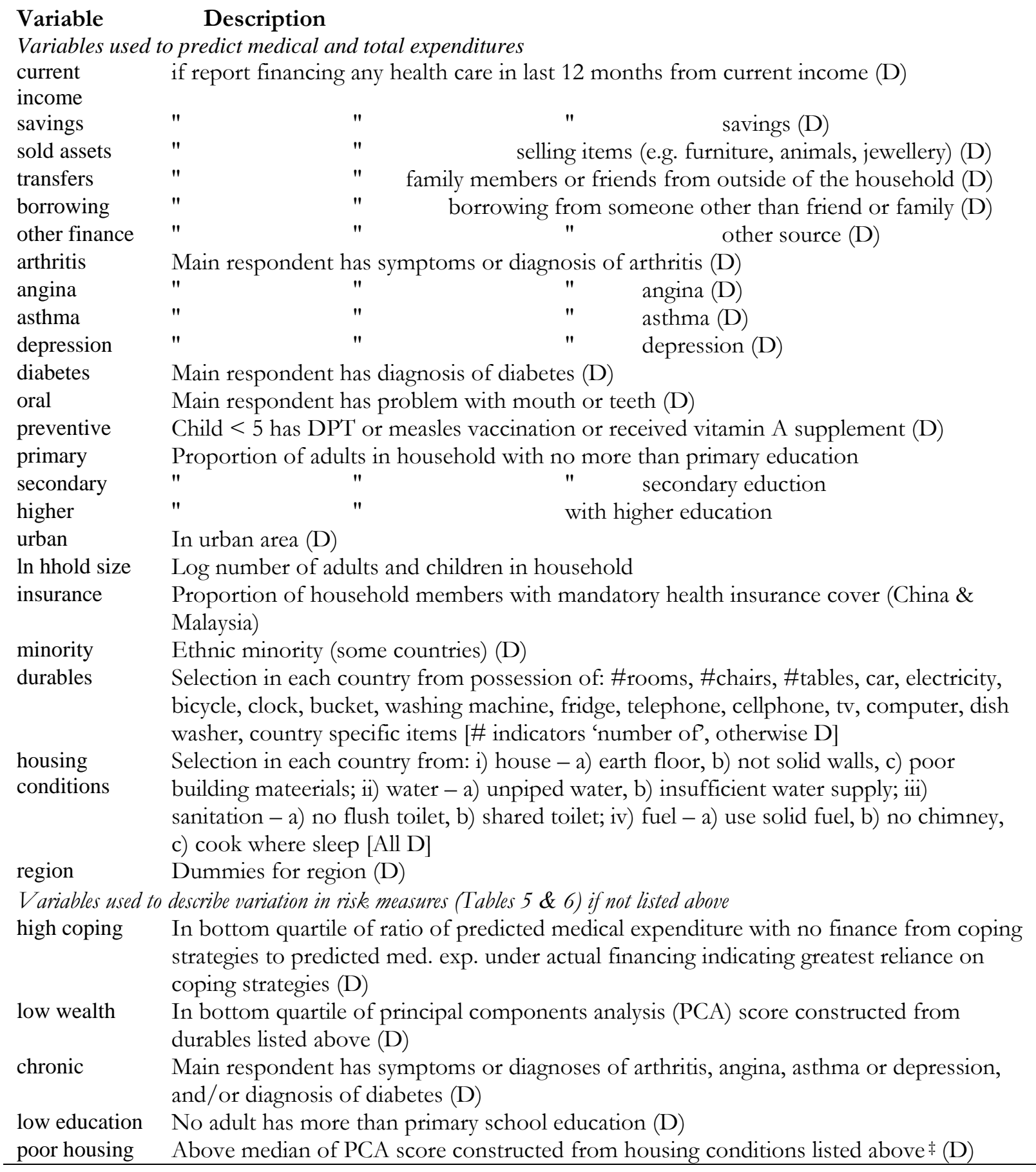

Notes: D dummy variable. 
Table A2: Means of dependent variables and main covariates included in prediction models by country

\begin{tabular}{lccccccc} 
& BGD & IND & PAK & CHN & LAO & MYS & PHL \\
\hline medical expenditure pc & 2334.8 & 2031.2 & 2076.1 & 976.08 & 245.21 & 182.18 & 2206.6 \\
total expenditure pc & 15650.6 & 11570.0 & 13647.8 & 6041.4 & 1648.8 & 3478.4 & 16100.6 \\
current income & 0.9348 & 0.8202 & 0.9301 & 0.9784 & 0.8800 & 0.8495 & 0.7681 \\
savings & 0.04709 & 0.1183 & 0.1240 & 0.1159 & 0.03516 & 0.1870 & 0.1783 \\
sold assets & 0.1057 & 0.1027 & 0.08610 & 0.02388 & 0.3800 & 0.01691 & 0.05728 \\
transfers & 0.1821 & 0.1887 & 0.2370 & 0.08685 & 0.08782 & 0.07865 & 0.2412 \\
borrowed & 0.2386 & 0.2524 & 0.2524 & 0.09393 & 0.03991 & 0.009203 & 0.1384 \\
other finance & 0.03506 & 0.05576 & 0.03088 & 0.04209 & 0.1144 & 0.02143 & 0.009761 \\
arthritis & 0.1914 & 0.2657 & 0.1378 & 0.1423 & 0.09738 & 0.1306 & 0.2085 \\
angina & 0.1903 & 0.2228 & 0.09696 & 0.05469 & 0.08612 & 0.1223 & 0.1793 \\
asthma & 0.1081 & 0.1129 & 0.06069 & 0.03143 & 0.05676 & 0.08216 & 0.1160 \\
depression & 0.1266 & 0.1865 & 0.09225 & 0.01586 & 0.02674 & 0.03635 & 0.05374 \\
diabetes & 0.03272 & 0.02879 & 0.02777 & 0.01699 & 0.004615 & 0.05644 & 0.02422 \\
oral & 0.4242 & 0.2966 & 0.2132 & 0.1964 & 0.2173 & 0.2132 & 0.3864 \\
preventive & 0.4018 & 0.2145 & 0.3391 & 0.1084 & 0.2673 & 0.2673 & 0.3163 \\
primary & 0.2694 & 0.2430 & 0.1249 & 0.2411 & 0.2359 & 0.2072 & 0.3075 \\
secondary & 0.07056 & 0.1199 & 0.09150 & 0.2958 & 0.1278 & 0.1514 & 0.3592 \\
higher & 0.08248 & 0.1404 & 0.1789 & 0.2699 & 0.1013 & 0.4296 & 0.1572 \\
urban & 0.3391 & 0.2731 & 0.4291 & 0.3965 & 0.2536 & 0.5898 & 0.5883 \\
ln hhold size & 1.5601 & 1.6299 & 1.9007 & 1.1735 & 1.6326 & 1.3286 & 1.5519 \\
\hline Sample size & 5025 & 6645 & 3888 & 3711 & 4254 & 5137 & 9035 \\
\hline
\end{tabular}

Notes: Expenditures are in national currency units. For Laos, 1=1000 kip. They are annual expenditures per capita. Models also include variables listed in Table A1. 